Article

\title{
Photoactuated Properties of Acetylene-Congeners Non-Metallic Dyes and Molecular Design for Solar Cells
}

\author{
Nan Gao ${ }^{1}$, Xiaochen Lin ${ }^{2}$, Jinglin Liu ${ }^{3}$, Yuanzuo $\mathrm{Li}^{1}{ }^{1, *(1)}$ and Yanhui Yang ${ }^{4,5, *}$ \\ 1 College of Science, Northeast Forestry University, Harbin 150040, China; nan_g@nefu.edu.cn \\ 2 Chemical Industry and Material College, Heilongjiang University, Harbin 150080, China; \\ xiaochenlinhd@sohu.com \\ 3 Department of Physics, Jiamusi University, Jiamusi 154001, China; jinglinliujms@yeah.net \\ 4 Institute of Advanced Synthesis, School of Chemistry and Molecular Engineering, Jiangsu National \\ Synergetic Innovation Center for Advanced Materials, Nanjing Tech University, Nanjing 211816, China \\ 5 School of Chemical and Biomedical Engineering, Nanyang Technological University, \\ Singapore 639798, Singapore \\ * Correspondence: yzli@nefu.edu.cn (Y.L.); Yhyang@njtech.edu.cn (Y.Y.); \\ Tel.: +86-451-8219-2245 (ext. 8211) (Y.L.)
}

Received: 6 September 2018; Accepted: 12 October 2018; Published: 18 October 2018

\begin{abstract}
This paper theoretically simulated (using DFT and TD-DFT in N,N-dimethylformamide (DMF) solvent) the photodynamic properties of three non-metallic dye molecules with $\mathrm{D}-\pi-\mathrm{A}_{1}-\pi-\mathrm{A}_{2}$ structure. The total photoelectric conversion efficiency (PCE) could be evaluated by the following parameters: the geometric structures, the electronic structures, and the absorption spectra, the analyses of charge difference density (CDD) and natural bond orbitals (NBO), the analyses of ionization potential (IP) and electron affinity (EA) from electronic contribution capacity, the reorganization energies $\left(\lambda_{h}, \lambda_{e}\right.$, and $\left.\lambda_{\text {total }}\right)$, and the chemical reaction parameter $\left(\mathrm{h}, \omega, \omega^{-}\right.$, and $\omega^{+}$) for intramolecular charge transfer (ICT) processing, the excited lifetime $(\tau)$ and the vertical dipole moment $\left(\mu_{\text {normol }}\right)$. The $\Delta G^{\text {inject }}$, the $\Delta G_{d y e}^{\text {regen }}$, the light harvesting efficiencies (LHE) and the excited lifetime $(\tau)$ were used to explain experimental $J_{S C}$. The experimental trend of $V_{O C}$ was explained by the calculation of $\Delta E_{C B}$ and $\mu_{\text {normol }}$. Moreover, the 15 dyes were designed by adding the electron-donor groups $\left(-\mathrm{OH},-\mathrm{NH}_{2}\right.$, and $\left.-\mathrm{OCH}_{3}\right)$ and the electron-acceptor groups $\left(-\mathrm{CF}_{3},-\mathrm{F}\right.$, and $-\mathrm{CN}$ ) to the LS-387 molecular skeleton, which improved electronic contribution, intramolecular charge transfer (ICT), and optoelectronic performance.
\end{abstract}

Keywords: dye-sensitized solar cells (DSSC); Acetylene-congeners; DFT; TD-DFT; photoelectric characteristics; ICT

\section{Introduction}

Since the beginning of the 21st century, environmental degradation and energy consumption have intensified. In order to realize the sustainable development of the environment and human society, it has become urgent to explore and develop new energy sources. Currently, silicon-based solar cells play a vital role in the field of energy with their excellent photoelectric conversion efficiency of about $26.6 \%$. However, their disadvantages, such as high cost, non-renewable raw materials, difficulty in preparation and not easy to be improved, have limited their wide application. Since O'Regan and Grätzel in 1991 [1] reported the highly efficient dye-sensitized solar cells (DSSCs) based on Ru complex with photoelectric conversion efficiency (PCE) of 7.1-7.9\%, more and more attention has been paid to DSSC due to its comparatively low cost and high efficiency [2-5]. DSSCs sensitized by free-metal organic dyes have 
been attracting attention by researchers for their clean and environment-friendly characteristics [6]. Particularly, the structural diversity and the simple synthetic routes of organic dye molecules provide the possibility to seek more competitive DSSC sensitizers [7]. For DSSCs, the core component is the sensitizing agent, which is divided into two kinds: metal-free organic dyes and metallic dyes [8]. Among them, organic dyes have the characteristics of low price, high extinction coefficient, adjustable structure, and light absorption characteristics by molecular design $[9,10]$. In order to achieve higher PCE, development of new structures, materials, and technologies has become important for researchers to improve conversion efficiency. From the viewpoint of molecular structures, donor- $\pi$ bridge-acceptor $(D-\pi-A)$ dyes have been widely used for non-metallic organic dye sensitizers; in addition, researchers have developed various molecular configurations (such as D-A- $\pi-A, D-(\pi-A)_{2}$ and $D-\pi-A_{4}$ etc.) to be used as the unit of the sensitizing agent for solar cells [11-13].

Non-metallic organic dyes with D- $\pi$-A- $\pi$-A structure have many advantages compared with the typical D- $\pi$-A structure [14-16], such as wider absorption spectra and improved intramolecular charge transfer ability. P Naik et al. reported non-metallic organic dyes with D- $\pi$-A- $\pi$-A structures (N1-3) from experiment and theory; dye N1 containing cyanoacetic acid as an acceptor unit showed a better PCE of 3.55\% [14], and DFT calculations provided deeper understanding of the mechanism of experimental photovoltaic parameters from the viewpoint of charge separation between occupied and unoccupied molecular orbitals as well as matching simulated spectral data with experimental data. G Wang et al. reported an $\mathrm{N}, \mathrm{N}$-di-p-tolylaniline-based $\mathrm{D}-\pi-\mathrm{A}_{1}-\pi-\mathrm{A}_{2}$ sensitizer $\mathrm{XD}_{1}$, obtaining a slightly higher PCE of 5.04\% [15]. The influence of DFBT and DPP on the electron-density distribution and structural feature were revealed by DFT. Recently, the molecules associated with the D- $\pi-A_{1}-\pi-A_{2}$ were reported [16], in which LS-387 displayed a high PCE of 5.61\%, with a higher short-circuit current $\left(J_{S C}\right)$ of $13.26 \mathrm{~mA} / \mathrm{cm}^{2}$ and open-circuit voltage $\left(V_{O C}\right)$ of $0.595 \mathrm{~V}$; furthermore, effective intramolecular charge transfer (ICT) characteristics can be adjusted by changing the unit of donors. To understand the experimental micromechanism, we analyzed parameters of molecular geometric structure, electron absorption spectroscopy, frontier MOs, energy levels and gaps, charge-transfer, electron injection free energy, and dye regeneration characteristic for LS-385, LS-386, and LS-387 through DFT and TD-DFT theory [17-19]. Moreover, based on LS-387, a series of molecules was designed to detect how the modification of the donor and acceptor affects the $J_{S C}$ and $V_{O C}$. The main purpose was focused on $\mathrm{D}-\pi-\mathrm{A}_{1}-\pi-\mathrm{A}_{2}$ organic materials, studying the relationship between structure and properties, and providing a design experience with specific functional groups.

\section{Computational Methods}

The quantum chemistry calculations were done using the GAUSSIAN09 software [20]. The ground state of three molecules (LS-385, LS-386, and LS-387) before and after absorbtion on $\left(\mathrm{TiO}_{2}\right)_{9}$ were fully optimized in vacuum and $\mathrm{N}, \mathrm{N}$-dimethylformamide (DMF) solvent with DFT [21], using B3lyp/6-31G(d) [22]. Based on the geometrical optimization of ground state, the relative vibration frequencies were computed at the same level, showing the minimum value of the optimal potential energy surface. The molecular bond lengths and dihedral angles, the frontier MOs, the energy gaps, the injection and recombination parameters were calculated. The absorption and emission characteristics of the three dyes in vacuum and solvent were obtained with TD-DFT [23] by using the CAM-B3LYP [24] functional with the 6-31G(d) basis set. Natural bond orbitals (NBO) analysis [25] based on the difference in charge between the ground state and the excited state was simulated using the NBO 6.0 program [26]. Furthermore, the Multiwfn 3.4 program [27] combined with the VMD 1.9.3 program [28] was used to visually analyze electrostatic potential (ESP) and average local ionization energy (ALIE). Moreover, we also calculated the first static hyperpolarization $\beta_{\text {tot }}$ of three molecules [29]. 
It is well known that the efficiency of DSSCs can be calculated from the $V_{O C}, J_{S C}$, fill factor (FF) and the incident solar power on the cell $\left(P_{i n}\right)$. Calculated efficiency can be written as follows [30]:

$$
\eta(\%)=\frac{V_{O C} \times J_{S C} \times \mathrm{FF}}{P_{\text {in }}} \times 100 \%
$$

The fill factor $(\mathrm{FF})$ is defined as the ratio of the maximum power that the battery can output to the theoretical maximum output power of the product of the $J_{S C}$ and $V_{O C}$ :

$$
\mathrm{FF}=\frac{I_{m} \times V_{m}}{V_{O C} \times J_{S C}}
$$

where $I_{m}$ and $V_{m}$ are the current and voltage corresponding to the maximum output power of the battery.

The $J_{S C}$ is an important representation of the PCE for DSSC, which can be expressed as [31]:

$$
J_{S C}=\int_{\lambda} \operatorname{IPCE}(\lambda) d y
$$

where IPCE is the incident photon-to-electron conversion efficiency, which can be obtained by the following calculation formula:

$$
\operatorname{IPCE}=\operatorname{LHE}(\lambda) \phi_{\text {inject }} \eta_{\text {collect }} \eta_{\text {reg }} I_{S}
$$

where $\operatorname{LHE}(\lambda)$ represents the light harvesting efficiency, and $\phi_{\text {inject }}$ indicates the electron injection efficiency, $\eta_{\text {collect }}$ is the charge collection efficiency, and $\eta_{\text {reg }}$ expresses the regeneration efficiency of dyes.

For particular DSSCs, the charge collection efficiency $\left(\eta_{\text {collect }}\right)$ is only a negligible difference in the same semiconductor electrode (universal is $\mathrm{TiO}_{2}$ ). Therefore, the $J_{S C}$ is determined by the remaining three parameters: LHE, $\phi_{\text {inject }}$, and $\eta_{\text {reg }}$. The LHE can be expressed as [32,33]:

$$
\mathrm{LHE}=1-10^{-A}=1-10^{-f}
$$

where $f$ is the calculated oscillator strength.

\section{Results and Discussion}

\subsection{Geometric Structures}

The ground state geometries of three organic molecules were calculated by using DFT/B3lyp with 6-31G(d) basis set in vacuum and DMF solvent. As shown in Figure 1a, the three molecules have a similar acceptor and $\pi$-bridge based on the benzene ring and the auxiliary acceptors of benzothiadiazole (BTZ) units near the acetylene bridge; the only difference is that the donor unit has different atom of oxygen, sulfur, and nitrogen. Based on the similarity of the three molecules, we defined six bond lengths $d_{1}$ to $d_{6}$ (see Figure 1a). In vacuum, $d_{1}$ of three molecules shows a great difference due to the differences in the donor group (such as $\mathrm{O}, \mathrm{S}$, and $\mathrm{N}$ atoms), and the single bonds $d_{1}$ show a shorter bond length for $\mathrm{C}-\mathrm{O}(1.360 \AA)$ and $\mathrm{C}-\mathrm{N}(1.379 \AA)$ (see Table 1), respectively. Moreover, in solvent, the $d_{1}$ for the three molecules is less than that in vacuum. The DFT calculation shows that the relatively short bond length may be derived from the hybridization between $s p^{2}$ and $s p^{3}$ carbon [34], and the corresponding bond length value has a good correlation with the photoelectric properties. By comparing $d_{2}$ to $d_{6}$ in vacuum and solvent, LS-387 has a shorter bond length, and thus LS-387 has better molecular stability. However, there is no significant difference between LS-386 and LS-385.

The acetylene bridge plays a crucial role in the coplanarity between the benzothiadiazole (BTZ) and the donor group (see Figure 1b). The two dihedral angles $\angle 1$ and $\angle 2$ in vacuum and DMF solvent 
are listed in Table 1. However, due to the spatial repulsive force between the nitrogen atom and the hydrogen atom of the benzene ring in the BTZ structure, the dihedral angle $(\angle 1)$ between BTZ and the adjacent phenyl group produces an angle of about $33^{\circ}$ (See Table 1 ). For $\angle 2$, compared with the vacuum, the dihedral angles in solvent are smaller, and LS-387 has the minimal dihedral angle $\left(0.5^{\circ}\right)$ compared with LS-385 and LS-386 in DMF solvent.

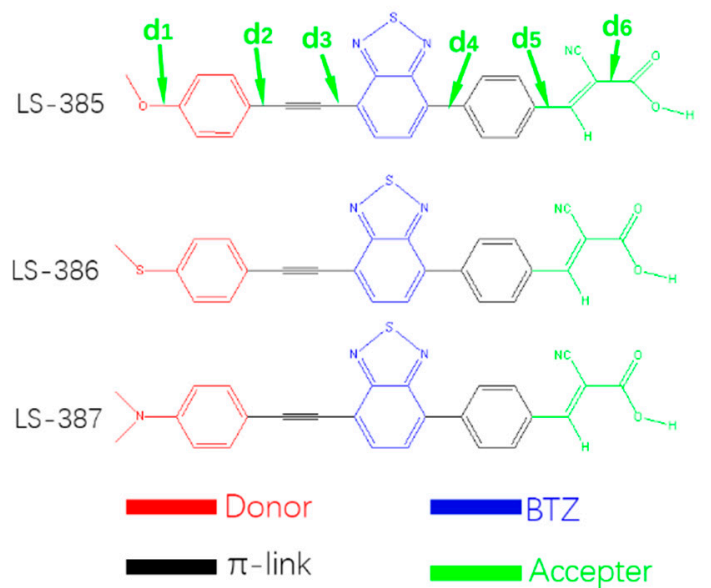

(a)

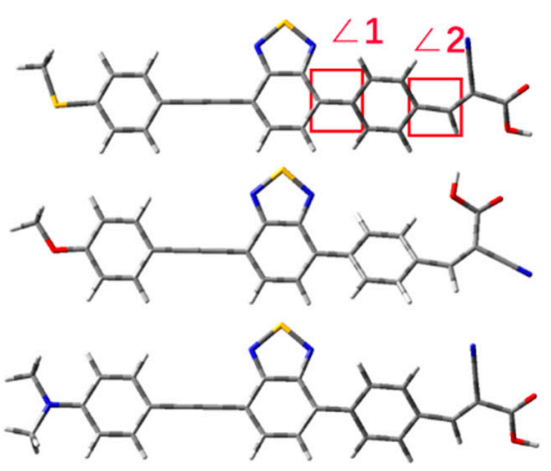

(b)

Figure 1. (a) shows molecular structures and names of LS-385, LS-386, and LS-387; (b) shows the ground-state optimized geometry by DFT calculations performed at the 6-31G(d) level.

Table 1. bond lengths $(\AA) d_{1}$ to $d_{6}$ and dihedral angles $\left(^{\circ}\right)$ of dyes in vacuum and DMF solvent, respectively.

\begin{tabular}{ccccccc}
\hline & \multicolumn{2}{c}{ LS-385 } & \multicolumn{2}{c}{ LS-386 } & \multicolumn{2}{c}{ LS-387 } \\
\cline { 2 - 7 } & Vacuum & Solvent & Vacuum & Solvent & Vacuum & Solvent \\
\hline$d_{1}(\AA)$ & 1.360 & 1.358 & 1.777 & 1.777 & 1.379 & 1.371 \\
$d_{2}(\AA)$ & 1.420 & 1.421 & 1.419 & 1.421 & 1.416 & 1.416 \\
$d_{3}(\AA)$ & 1.413 & 1.415 & 1.413 & 1.415 & 1.410 & 1.411 \\
$d_{4}(\AA)$ & 1.477 & 1.477 & 1.477 & 1.477 & 1.476 & 1.476 \\
$d_{5}(\AA)$ & 1.458 & 1.455 & 1.452 & 1.450 & 1.451 & 1.448 \\
$d_{6}(\AA)$ & 1.494 & 1.492 & 1.489 & 1.488 & 1.488 & 1.488 \\
$\angle 1$ & 32.4 & 34.4 & 33.2 & 34.6 & 32.4 & 33.5 \\
$\angle 2$ & 26.8 & 25.5 & 1.4 & 0.7 & 1.5 & 0.5 \\
\hline
\end{tabular}

\subsection{Electronic Structure}

Electronic structure analysis gives the charge transfer characteristics. The energy level of HOMO, LUMO, and energy gaps $\left(\Delta_{H}=|H-L|\right)$ and electron density of the frontier MOs are the important parameter reflecting the electronic excitation and transition characteristics of the dyes, shown in Table S1 and Figures 2 and 3. As shown in Figure 2, HOMO and LUMO belong to the $\pi$ and $\pi^{*}$, respectively [35]. For LS-385 and LS-386, the electron density of HOMO is distributed on the D- $\pi-A_{1}-\pi$ part; the electron density of LUMO resides in the $\pi-A_{1}-\pi-A_{2}$ part; and for LUMO+1, the electron density is the distribution on the $A_{1}-\pi-A_{2}$ part; most of the electrons are in the acceptor; and for the HOMO-1, the electron is distributed throughout the molecule. LS-385 and LS-386 exhibit a similar electron density distribution. For LS-387, the LUMO distribution is not significantly different from the other two molecules, but HOMO energies have a good aggregation on the donor, indicating that LS-387 has a better push-pull effect. 


\begin{tabular}{|c|c|c|c|c|}
\hline & HOMO-1 & HOMO & LUMO & LUMO+1 \\
\hline LS-385 & & & & \\
\hline LS-386 & & & & \\
\hline
\end{tabular}

Figure 2. Frontier molecular orbital of LS-385, LS-386, and LS-387 calculated under B3LYP/6-31G(d) level.

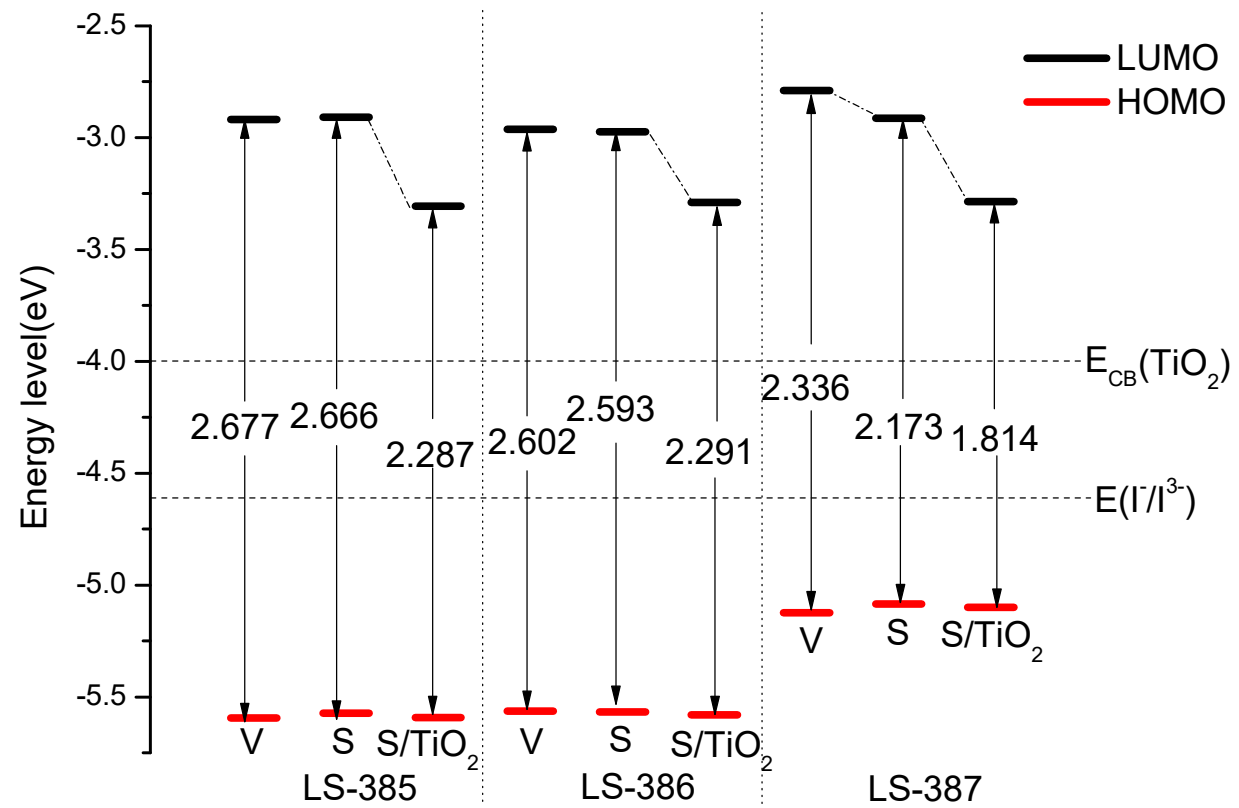

Figure 3. The molecules energy levels diagram of LS-385, LS-386, LS-387 (V, S, and S/TiO 2 representative in vacuum, in solvent and dyes $/ \mathrm{TiO}_{2}$ in solvent, respectively).

The driving force for electron injection and oxidation dye regeneration can be evaluated by the energy levels. As shown in Figure 3, the LUMO energy levels of three molecules are higher than the conduction band $(\mathrm{CB})$ of $\mathrm{TiO}_{2}\left[E_{\mathrm{CB}}\left(\mathrm{TiO}_{2}\right)\right]$ of $-4.0 \mathrm{eV}$, which facilitates electron injection from the excited dyes to the $\mathrm{TiO}_{2}$ electrode. The LUMO energy levels of LS-385, LS-386, and LS-387 are lower than that of the redox potential $I^{-} / I^{3-}(-4.60 \mathrm{eV}[36,37])$, which means that the electrolyte can release electrons into the oxidative dye. From Table S1, the HOMO energies of the three molecules in vacuum can be arranged as LS-387 $(-5.125 \mathrm{eV})>$ LS-386 $(-5.564 \mathrm{eV})>$ LS-385 $(-5.595 \mathrm{eV})$, it is probably because the $\mathrm{N}$ atom in LS-387 donor is effective in reducing the HOMO level. The LUMO energies are in following order: LS-387 $(-2.789 \mathrm{eV})>$ LS-385 $(-2.918 \mathrm{eV})>\mathrm{LS}-386(-2.962 \mathrm{eV})$, it can be concluded that both HOMO and LUMO of LS-387 are greater than for other molecules. Higher HOMO energy can result in higher electron donation capabilities, meaning that LS-387 has strong electronic donation capabilities. In solvent, the HOMO and LUMO of LS-385 and LS-386 do not show obvious changes compared with vacuum (see in Figure 3). While for LS-387 in solvent, the HOMO is greater than that in vacuum, and the LUMO is less than that in vacuum.

The HOMO and LUMO energy levels after adsorption on titanium dioxide are shown in Figure 3. The HOMO energy of LS-387/s and LS-387/s $+\mathrm{TiO}_{2}$ are $-5.085 \mathrm{eV}$ and $-5.100 \mathrm{eV}$ (see Table S1), respectively. It is obvious that the $\mathrm{HOMO}$ has changed slightly before and after adsorption onto $\mathrm{TiO}_{2}$. For LUMO, LS-387/s + $\mathrm{TiO}_{2}(-3.286 \mathrm{eV})$ is significantly higher than LS-387/s $(-2.912 \mathrm{eV})$. A similar trend also occurs in the other two molecules. In addition, the energy gap also shows a downward 
trend compared with isolated molecules; their values are: $\mathrm{LS}-385 / \mathrm{s}+\mathrm{TiO}_{2}(2.287 \mathrm{eV}), \mathrm{LS}-386 / \mathrm{s}+\mathrm{TiO}_{2}$ (2.291 eV), and LS-387/s $+\mathrm{TiO}_{2}(1.814 \mathrm{eV})$.

The charge difference density (CDD) of the three molecules was used to study the charge transfer characteristics (see Figure S1). The CDD map clearly shows the change of charge density between the ground state and the excited state during photo-excitation, [38,39], indicating the ICT direction. As shown in Figure S1, the electron density is mainly distributed in BTZ units and acceptor, and the hole density is mainly distributed in donor, $\pi$-bridge, and BTZ, therefore, $\mathrm{CI}$ is from donor to acceptor. Figure 4 shows the $\mathrm{CDD}$ of the dye and $\mathrm{TiO}_{2}$ complex model, which has a more obvious charge separation compared with the isolated dye molecules. As shown in Figure 4, for $\mathrm{LS}-385 / \mathrm{TiO}_{2}$ and $\mathrm{LS}-386 / \mathrm{TiO}_{2}$, the electron density is gradually transferred into $\mathrm{TiO}_{2}$ clusters with the increase of energy levels, and the hole density is gathered in the site of the donor. For LS-387/ $\mathrm{TiO}_{2}$, with the increase of the energy levels, the separation of electrons and holes become gradually obvious; for $S_{4}-S_{6}$ it seems that the electrons tend to be distributed in $\mathrm{TiO}_{2}$ clusters on one site, while the hole distribution is on the molecule near the site of the donor, thus enhancing the ICT characteristics of LS-387.

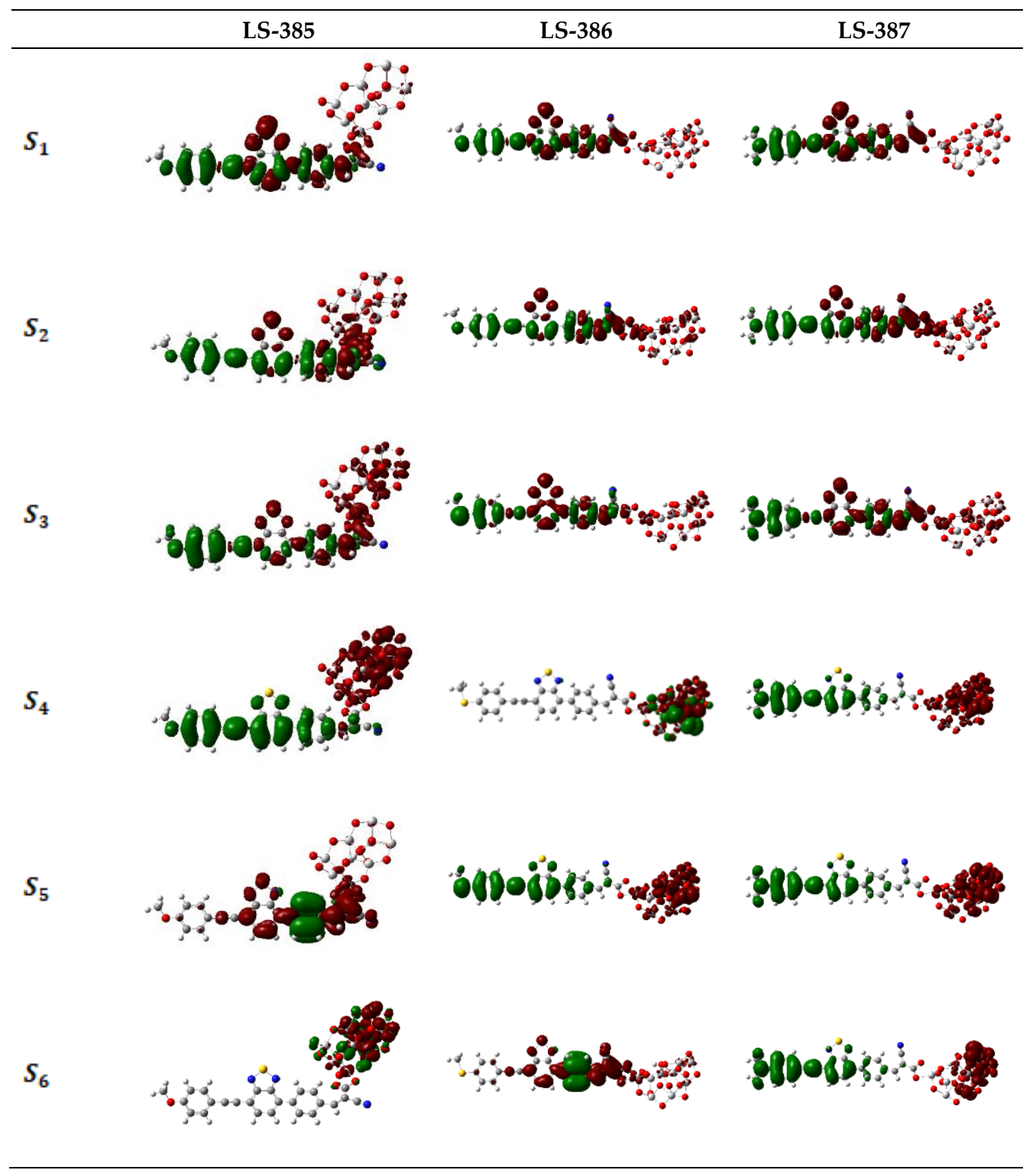

Figure 4. Charge difference density (CDD) of the selected excited state for dyes $/\left(\mathrm{TiO}_{2}\right)_{9}$ complexes in solvent. (Green and red stand for the hole and electron, respectively). 


\subsection{Electronic Absorption Spectra}

Based on the geometry optimization of the ground-state, the excited states of the three dyes and dyes $/ \mathrm{TiO}_{2}$ were calculated based on TD-DFT/cam-B3lyp/6-31G(d) in vacuum and DMF solvent. As compared, a diffused basis set $6-31+\mathrm{G}(\mathrm{d}, \mathrm{p})$ was used to calculate $\lambda_{\max }$ on the basis of optimization with the same basis set, and the values of $\lambda_{\max }$ for LS-385, LS-386, LS-387, are $543.27 \mathrm{~nm}, 564.42 \mathrm{~nm}$ and $671.80 \mathrm{~nm}$, respectively, which are greatly red-shifted in comparison with experiment $(425 \mathrm{~nm}$, $425 \mathrm{~nm}$, and $475 \mathrm{~nm}$ ). Therefore, the basis set $6-31 \mathrm{G}(\mathrm{d})$ was used in the following calculations due to the wide application and certain accuracy. As shown in Table 2, the maximum wavelength $\left(\lambda_{\max }\right)$ of the three molecules in vacuum can be arranged as follows: LS-387 $(449.11 \mathrm{~nm})>$ LS-386 $(426.65 \mathrm{~nm})>$ LS-385 $(421.57 \mathrm{~nm})$, and LS-387 has about $25 \mathrm{~nm}$ red-shift. In solvent, the $\lambda_{\max }$ is in order: LS-387 $(470.40 \mathrm{~nm})>$ LS-386 $(428.83 \mathrm{~nm}) \approx$ LS-385 $(428.47 \mathrm{~nm})$, and LS-387 also has about $40 \mathrm{~nm}$ red-shift compared with LS-385 and LS-386, which is due to the fact that LS-387 has a smaller energy gap to exhibit a high molar extinction coefficient and produce more electrons under visible light. Meanwhile, the LS-387 also showed higher $V_{O C}$ in the experiment [16].

Table 2. The excitation energy and oscillator strength obtained by TD-DFT//Cam-B3LYP/6-31G(d) in vacuum and $\mathrm{N}, \mathrm{N}$-dimethylformamide (DMF) solvent.

\begin{tabular}{|c|c|c|c|c|c|}
\hline & Dye & State & $E_{g} / \lambda_{\max }$ & $\mathbf{F}$ & Main CI \\
\hline \multirow{9}{*}{ Gas } & \multirow{3}{*}{ LS-385 } & $S_{1}$ & $2.9410 / 421.57$ & 1.1646 & $0.65655(\mathrm{H} \rightarrow \mathrm{L})$ \\
\hline & & $S_{2}$ & $3.8832 / 319.29$ & 0.5094 & $0.54620(\mathrm{H} \rightarrow \mathrm{L}+1)$ \\
\hline & & $S_{3}$ & $4.1821 / 296.46$ & 0.0214 & $0.57628(\mathrm{H}-1 \rightarrow \mathrm{L})$ \\
\hline & \multirow{3}{*}{ LS-386 } & $S_{1}$ & $2.9060 / 426.65$ & 0.7495 & $0.66540(\mathrm{H} \rightarrow \mathrm{L})$ \\
\hline & & $S_{2}$ & $3.8161 / 324.90$ & 0.0063 & $0.43530(\mathrm{H}-9 \rightarrow \mathrm{L})$ \\
\hline & & $S_{3}$ & $4.0477 / 306.31$ & 0.7171 & $0.51222(\mathrm{H} \rightarrow \mathrm{L}+1)$ \\
\hline & \multirow{3}{*}{ LS-387 } & $S_{1}$ & $2.7606 / 449.11$ & 1.2886 & $0.62767(\mathrm{H} \rightarrow \mathrm{L})$ \\
\hline & & $S_{2}$ & $3.7304 / 332.36$ & 0.4445 & $0.55969(\mathrm{H} \rightarrow \mathrm{L}+1)$ \\
\hline & & $S_{3}$ & $3.9155 / 316.65$ & 0.0101 & $0.58567(\mathrm{H}-1 \rightarrow \mathrm{L})$ \\
\hline \multirow{9}{*}{ Solvent } & \multirow{3}{*}{ LS-385 } & $S_{1}$ & $2.8936 / 428.47$ & 1.3613 & $0.64539(\mathrm{H} \rightarrow \mathrm{L})$ \\
\hline & & $S_{2}$ & $3.7665 / 329.18$ & 0.4518 & $0.52513(\mathrm{H} \rightarrow \mathrm{L}+1)$ \\
\hline & & $S_{3}$ & $4.1529 / 298.55$ & 0.0581 & $0.53107(\mathrm{H}-1 \rightarrow \mathrm{L})$ \\
\hline & \multirow{3}{*}{ LS-386 } & $S_{1}$ & $2.8912 / 428.83$ & 1.5163 & $0.62471(\mathrm{H} \rightarrow \mathrm{L})$ \\
\hline & & $S_{2}$ & $3.7748 / 328.46$ & 0.4001 & $0.50349(\mathrm{H} \rightarrow \mathrm{L}+1)$ \\
\hline & & $S_{3}$ & $4.0716 / 304.51$ & 0.1023 & $0.48781(\mathrm{H}-1 \rightarrow \mathrm{L})$ \\
\hline & \multirow{3}{*}{ LS-387 } & $S_{1}$ & $2.6357 / 470.40$ & 1.4452 & $0.61544(\mathrm{H} \rightarrow \mathrm{L})$ \\
\hline & & $S_{2}$ & $3.5912 / 345.25$ & 0.4431 & $0.52970(\mathrm{H} \rightarrow \mathrm{L}+1)$ \\
\hline & & $S_{3}$ & $3.7958 / 326.63$ & 0.0016 & $0.53890(\mathrm{H}-1 \rightarrow \mathrm{L})$ \\
\hline \multirow{9}{*}{ Solvent $+\mathrm{TiO}_{2}$} & \multirow{3}{*}{ LS-385 } & $S_{1}$ & $2.8183 / 439.92$ & 1.5757 & $0.44929(\mathrm{H} \rightarrow \mathrm{L}+1)$ \\
\hline & & $S_{2}$ & $3.5424 / 350.00$ & 0.2339 & $0.31156(\mathrm{H} \rightarrow \mathrm{L}+7)$ \\
\hline & & $S_{3}$ & $4.0393 / 306.94$ & 0.0108 & $0.37487(\mathrm{H} \rightarrow \mathrm{L})$ \\
\hline & \multirow{3}{*}{ LS-386 } & $S_{1}$ & $2.8292 / 438.23$ & 1.8788 & $0.54394(\mathrm{H} \rightarrow \mathrm{L})$ \\
\hline & & $S_{2}$ & $3.6151 / 342.96$ & 0.3837 & $0.28510(\mathrm{H} \rightarrow \mathrm{L}+7)$ \\
\hline & & $S_{3}$ & $4.0090 / 309.26$ & 0.0084 & $0.41495(\mathrm{H}-1 \rightarrow \mathrm{L})$ \\
\hline & \multirow{3}{*}{ LS-387 } & $S_{1}$ & $2.5615 / 484.02$ & 1.7597 & $0.50407(\mathrm{H} \rightarrow \mathrm{L})$ \\
\hline & & $S_{2}$ & $3.4105 / 363.53$ & 0.3750 & $0.30764(\mathrm{H} \rightarrow \mathrm{L}+8)$ \\
\hline & & $S_{3}$ & $3.6944 / 335.60$ & 0.0863 & $0.43001(\mathrm{H}-1 \rightarrow \mathrm{L})$ \\
\hline
\end{tabular}

As shown in Figure 5a, the UV-Vis absorption spectra of the three dye molecules in vacuum and solvent cover the near-ultraviolet and visible regions, and they all have distinct double absorption peaks. The highest absorption peak is due to the first excited state $\left(S_{1}\right)$, and its electronic transition is from HOMO to LUMO, showing better ICT characteristics. For LS-385 in vacuum and solvent, the lower absorption peak (located near $325 \mathrm{~nm}$ ) is mainly attributed to the second excited state $\left(S_{2}\right)$, 
and the corresponding electronic transition is from HOMO to LUMO +1 ( $f=0.5094$ and 0.4518 in vacuum and solvent, respectively). It can be seen from the similar charge distribution of LUMO and $\mathrm{LUMO}+1$ that the electron transfer pathway is similar to that of $S_{1}$. For LS-386 in solvent, the main absorption peak at $330 \mathrm{~nm}$ corresponds to the second excited state $\left(S_{2}\right)$, it shows an electron transition from HOMO to LUMO + 1 ( $f=0.4001)$; and for LS-387 in vacuum and solvent, the second absorption peak (near $340 \mathrm{~nm}$ ) corresponds to a transition from $\mathrm{HOMO} \rightarrow \mathrm{LUMO}+1$ in the S2 $(f=0.4445$ and 0.4431 in vacuum and solvent, respectively); similarly, the transition of this state is the same as $S_{1}$. In summary, $\lambda_{\max }$ is mainly ICT derived from the $S_{1}$ excited state. Figure $5 \mathrm{~b}$ shows the UV-Vis absorption spectra of three dyes after adsorbing on $\mathrm{TiO}_{2}$ cluster, and the absorption spectra of three dyes having red-shifted compared to isolated dyes. Moreover, the molar extinction coefficients of LS-386 and LS-387 have a marked increase of $7.64 \times 10^{4} \mathrm{M}^{-1} \mathrm{~cm}^{-1}$ and $7.14 \times 10^{4} \mathrm{M}^{-1} \mathrm{~cm}^{-1}$, respectively. Therefore, the absorption spectrum of dyes after adsorption has obviously changed, which can increase the ICT and the electron transfers into $\mathrm{TiO}_{2} \mathrm{CB}$.

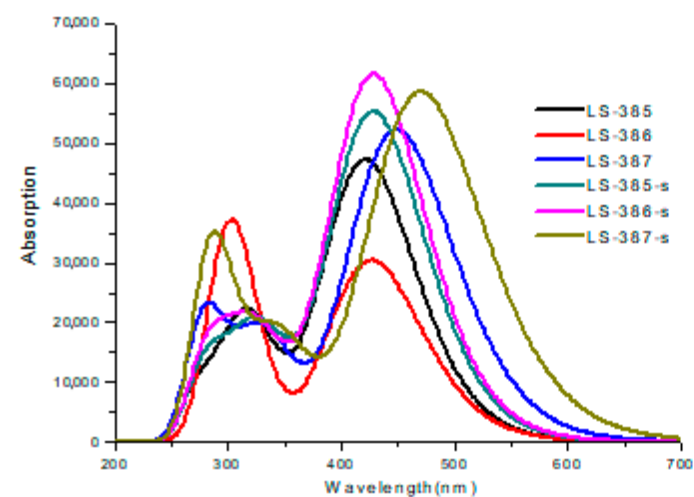

(a)

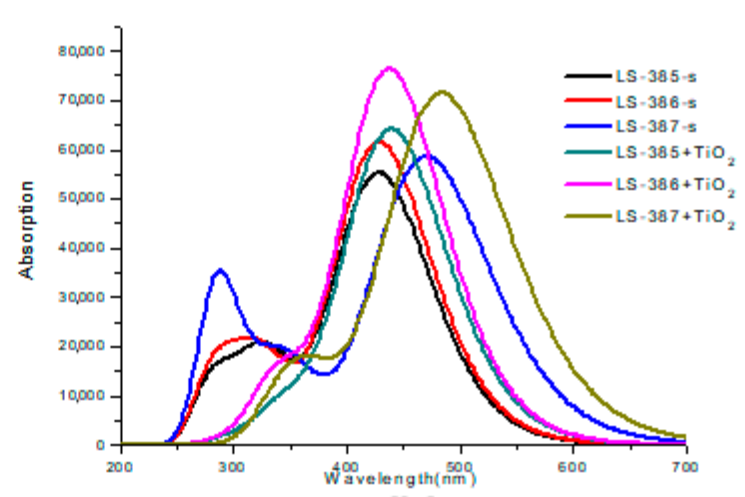

(b)

Figure 5. UV-Vis Absorption spectra of LS-385, LS-386, and LS-387 (where (a) represents in vacuum and (b) represents in DMF solvent).

The analysis of natural bond orbitals (NBO) provides a deeper understanding of the optical excitation properties of dyes. As shown in Table 3 , the difference in charge $\left(\Delta \mathrm{q}\right.$, from $S_{0}$ to $\left.S_{1}\right)$ of the three molecules at the donor group indicates that LS-387 and LS-386 have a strong electron-providing ability compared with LS-385. This is probably because oxygen atoms on the LS-385 donor have poor electron capacity. Compared with LS-385 and LS-386, the BTZ group of LS-387 sneaked into the electron collection of the receptor. Besides, $\Delta \mathrm{q}$ on the acetylene bridge of LS-385 (-0.09), LS-386 (-0.08), and LS-387 (-0.086), provide an ICT channel. Also, the acceptor of $\Delta \mathrm{q}$ shows the following: LS-387 (0.09) > LS-386 (0.08) $\approx$ LS-385 (0.08), which illustrates that LS-387 has a strong ability to accept electrons. As a result, LS-387 should stimulate more electron transfer in the optical excitation mechanism.

Table 3. Natural Bond Orbital Analysis (Atomic Charge in a.u.) for the Ground State $\left(S_{0}\right)$ and Excited State $\left(S_{1}\right)$ of the dyes with D- $\pi$-A- $\pi$-A fragments.

\begin{tabular}{ccccccc}
\hline Dye & & Donor & $\pi$ & Acetylene Bridge & BTZ & Acceptor \\
\hline \multirow{4}{*}{ LS-385 } & $S_{0}$ & -0.18 & 0.30 & 0.02 & -0.07 & -0.06 \\
& $S_{1}$ & -0.16 & 0.46 & 0.11 & -0.27 & -0.14 \\
& $\Delta \mathrm{q}$ & -0.02 & -0.16 & -0.09 & 0.20 & 0.08 \\
\hline \multirow{3}{*}{ LS-386 } & $S_{0}$ & 0.14 & -0.04 & 0.03 & -0.05 & -0.08 \\
& $S_{1}$ & 0.28 & 0.004 & 0.11 & -0.23 & -0.16 \\
& $\Delta \mathrm{q}$ & -0.14 & -0.036 & -0.08 & 0.18 & 0.08 \\
\hline \multirow{2}{*}{ LS-387 } & $S_{0}$ & 0.02 & 0.14 & 0.004 & -0.07 & -0.09 \\
& $S_{1}$ & 0.13 & 0.31 & 0.09 & -0.36 & -0.18 \\
& $\Delta \mathrm{q}$ & -0.11 & -0.17 & -0.086 & 0.29 & 0.09 \\
\hline
\end{tabular}




\subsection{Analysis of Charge Injection Capability.}

An important indicator for assessing injection capacity is ionization potential (IP) and electron affinity (EA) for holes and electrons, respectively [40-43]. IP represents the energy change of electron extraction or hole addition. EA means the change in energy of hole extraction or electron absorption [35]. As shown in Table S2, the IP of the three molecules in the order: LS-385 $(6.67 \mathrm{eV})>$ LS-386 $(6.64 \mathrm{eV})>$ LS-387 $(6.23 \mathrm{eV})$, and the smallest LS-387 has the better injection capacity. The EA of the three dyes is as follows: LS-387 $(1.80 \mathrm{eV})<$ LS-385 $(1.93 \mathrm{eV})<$ LS-386 $(1.99 \mathrm{eV})$, and the higher the EA, the higher the electronic acceptability becomes [44]; so LS-386 has a greater ability to inject electrons. Nevertheless, the IP of the three dyes in solvent goes down compared with vacuum, and LS-387 in solvent has the lower IP of $4.92 \mathrm{eV}$, which also indicates that LS-387 is more advantageous for extracting electrons. The $E_{\text {fund }}=I P-E A$ is used to characterize the electronic contribution of the dye molecules. As shown in Table S2, the $E_{\text {fund }}$ of the three dyes in vacuum is as follows: LS-385 $(4.74 \mathrm{eV})>$ LS-386 $(4.65 \mathrm{eV})>$ LS-387 $(4.43 \mathrm{eV})$, and in solvent the dye of LS-387 has a lower $E_{\text {fund }}$ of $1.76 \mathrm{eV}$, which is in agreement with the experiment [16]. The $E_{\text {fund }}$ is vacuum > solvent, therefore, the molecules in the DMF solvent produce a better electronic capability than in vacuum.

\subsection{Analysis of Chemical Reaction Parameters}

Another method for evaluating the charge transfer properties of sensitizers is the recombination energy [35], and the Marcus theory gives the rate formula [45]:

$$
K_{E T}=\mathrm{A} \exp \left[-\lambda / 4 K_{B} T\right]
$$

where $\lambda$ is the recombination energy, $T$ is the temperature, $\mathrm{A}$ is the electron coupling, and $K_{B}$ is the Boltzmann constant.

Quantitative methods provide a feasible method for studying charge transport in organic material systems [46] and for calculating hole and electron recombination energy $\left(\lambda_{h}\right.$ and $\left.\lambda_{e}\right)$, which can be calculated [46]:

$$
\begin{aligned}
& \lambda_{h}=\left(E_{0}^{-}-E_{-}\right)+\left(E_{0}^{-}-E_{0}\right) \\
& \lambda_{e}=\left(E_{0}^{+}-E_{+}\right)+\left(E_{0}^{+}-E_{0}\right)
\end{aligned}
$$

The above parameters can be obtained by optimizing the neutral molecular structure and the anion (cation) structure. As shown in Table $4, \lambda_{h}$ of the three molecules in vacuum can be arranged: LS-385 $(0.25 \mathrm{eV})>$ LS-386 $(0.20 \mathrm{eV})>$ LS-387 $(0.18 \mathrm{eV})$; and $\lambda_{e}$ can be arranged in the order: LS-386 $(0.42 \mathrm{eV})>$ LS-385 $(0.37 \mathrm{eV})>$ LS-387 $(0.33 \mathrm{eV})$. Table 4 also shows the $\lambda_{h}$ and $\lambda_{e}$ in DMF solvent has a noticeable decrease, and LS-387 has a lower recombination energy in vacuum and solvent, which will produce better molecular charge transfer and thus better photoelectric performance.

Table 4. The reorganization energy $\left(\lambda_{h}\right.$ and $\left.\lambda_{e}\right)$ and the chemical reactivity parameters $\lambda_{h}$ and $\lambda_{e}$ of LS-385, LS-386 and LS-387 in vacuum and DMF solvent.

\begin{tabular}{ccccccc}
\hline & \multicolumn{2}{c}{ LS-385 } & \multicolumn{2}{c}{ LS-386 } & \multicolumn{2}{c}{ LS-387 } \\
\cline { 2 - 7 } & Vacuum & Solvent & Vacuum & Solvent & Vacuum & Solvent \\
\hline$\lambda_{h}$ & 0.25 & 0.24 & 0.20 & 0.19 & 0.18 & 0.13 \\
$\lambda_{e}$ & 0.37 & 0.34 & 0.42 & 0.29 & 0.33 & 0.27 \\
$\mathrm{~h}$ & 2.37 & 1.09 & 2.32 & 1.08 & 2.22 & 0.88 \\
$\omega$ & 3.91 & 8.41 & 4.01 & 8.57 & 3.64 & 9.27 \\
$\omega^{+}$ & 2.05 & 6.41 & 2.14 & 6.56 & 1.91 & 7.36 \\
$\omega^{-}$ & 6.35 & 10.69 & 6.46 & 10.86 & 5.93 & 11.40 \\
\hline
\end{tabular}

Electrochemical parameters (such as chemical hardness h, electrophilic index $\omega$, electron accepting power $\omega^{+}$, and electron donating ability $\omega^{-}$) are important factors affecting the efficiency of 
photovoltaic cells. The relevant calculated data are in Table 4. The parameter $\mathrm{h}$ represents the impedance for ICT [47]. Low chemical hardness is characterized by low ICT resistance, which in turn increases the acceptability of electrons [40]. Therefore, good dyes should have low $\mathrm{h}$ and higher $\omega^{+}$. As shown in Table 4, LS-387 $(\mathrm{h}=2.22 \mathrm{eV})$ has a lower chemical hardness compared with that of LS-385 $(\mathrm{h}=2.37 \mathrm{eV})$ and LS-386 $(\mathrm{h}=2.32 \mathrm{eV})$, and the $\mathrm{h}$ of three molecules is: vacuum > solvent, indicating that LS-387 has a smaller ICT resistance in solvent. Moreover, LS-387 in solvent has a higher electron accepting power $\left(\omega^{+}=7.36\right)$ than LS-385 $\left(\omega^{+}=6.41\right)$ and LS-386 $\left(\omega^{+}=6.56\right)$, which implies that LS-387 exhibits a higher electron withdrawing capacity through its receptor moiety. Taken the two parameters into account, it can be inferred that LS-387 will have higher ICT and PCE. The higher the electrophilic index $(\omega)$, the higher the stability of the dye becomes. In solvent, LS-387 has a higher electrophilicity index $(\omega=9.27 \mathrm{eV})$ compared with that of LS-385 $(\omega=8.41 \mathrm{eV})$ and LS-386 $(\omega=8.57 \mathrm{eV})$, and the $\omega$ of three dyes is solvent > vacuum, which indicate LS-387 has a higher energetic stability. In order to obtain a large electron supply capacity, the hope is that the molecule has a lower electron donating energy. Table 4 shows that LS-387 in vacuum has a lower electron donating power $\left(\omega^{-}=5.93 \mathrm{eV}\right)$ compared with that of LS-385 $\left(\omega^{-}=6.35 \mathrm{eV}\right)$ and LS-386 $\left(\omega^{-}=6.46 \mathrm{eV}\right)$; however, in solvent, the three dyes have a higher $\omega^{-}$compared with that in vacuum. Never the less, comprehensive consideration on the chemical reactivity parameters indicates that LS-387 in solvent has a better chemical reactivity parameter, resulting in a better photoelectric performance of LS-387 among the three dyes.

\subsection{Performance of DSSCs Based on Dyes}

The LHE is an important parameter to measure the performance of sensitizer and to evaluate $J_{S C}$. Table 5 shows LS-387 (0.9485) in vacuum has a higher LHE compared with LS-385 (0.9315) and LS-386 (0.8220). Moreover, in DMF solvent the LHE of them increases to different degrees. The higher LHE will lead to higher $J_{S C}$, therefore, LS-387 will have better photoelectric conversion performance due to its higher LHE.

Table 5. The $V_{R P}$, the light harvesting efficiencies (LHE), the electron injection free energy ( $\Delta G^{\text {inject }}$, in $\mathrm{eV})$, the oxidation potential of the dye in ground state $\left(E_{o x}^{d y e *}\right.$, in $\left.\mathrm{eV}\right)$, the oxidation potential of the dye in excited state $\left(E_{o x}^{\text {dye }}\right.$, in $\left.\mathrm{eV}\right)$, the dye regeneration free energy $\left(\Delta G_{d y e}^{\text {regen }}\right.$, in $\left.\mathrm{eV}\right)$, and the vertical dipole moment of $\left(\mu_{\text {normol }}\right.$, in Debye) in vacuum and DMF solvent.

\begin{tabular}{ccccccc}
\hline & \multicolumn{2}{c}{ LS-385 } & \multicolumn{2}{c}{ LS-386 } & \multicolumn{2}{c}{ LS-387 } \\
\cline { 2 - 7 } & Vacuum & Solvent & Vacuum & Solvent & Vacuum & Solvent \\
\hline$V_{R P}$ & 0.673 & 0.660 & 0.671 & 0.662 & 0.818 & 0.776 \\
LHE & 0.9315 & 0.9565 & 0.8220 & 0.9695 & 0.9485 & 0.9641 \\
$\Delta G^{\text {inject }}$ & -1.346 & -1.319 & -1.342 & -1.324 & -1.636 & -1.551 \\
$\Delta G_{\text {dye }}^{\text {regen }}$ & 0.995 & 0.975 & 0.964 & 0.968 & 0.525 & 0.485 \\
$E_{\text {ox }}^{\text {dye }}$ & 5.595 & 5.575 & 5.564 & 5.568 & 5.125 & 5.085 \\
$E_{\text {dye* }}^{\text {dye }}$ & 2.654 & 2.681 & 2.658 & 2.677 & 2.364 & 2.449 \\
$\mu_{\text {normol }}$ & -10.6528 & -12.6125 & -6.1017 & -6.7901 & -10.5313 & -12.9878 \\
\hline
\end{tabular}

In addition, the influence of the electron injection efficiency of the excited state $\left(\phi_{\text {inject }}\right)$ on the $J_{S C}$ was evaluated. The $\phi_{\text {inject }}$ is closely related to the driving force of electron injection $\left(\Delta G_{\text {inject }}\right)$. The Marcus theory determines the electron transfer ability of an excited state dye into a semiconductor $[48,49]$ :

$$
\kappa_{\text {inject }}=\left[V_{R P}\right] \frac{2}{h}\left(\frac{\pi}{\lambda k_{B} T}\right)^{\frac{1}{2}} \exp \left[-\frac{\left(\Delta G_{\text {inject }}+\lambda\right)^{2}}{4 \lambda k_{B} T}\right]
$$


where $\kappa_{\text {inject }}$ is the rate constant (in $S^{-1}$ ) of the electron injection from dye to $\mathrm{TiO}_{2}, \mathrm{~h}$ is the Planck constant, $k_{B}$ is the Boltzmann constant, $\Delta G_{\text {inject }}$ is the electron injection free energy, $\lambda$ is the reorganization energy. $\left|V_{R P}\right|$ is the coupling constant between the reagent and the product potential curves. It can be concluded from the above equation that a larger $\left|V_{R P}\right|$ will increase $\kappa_{\text {inject }}$ and result in faster electron injection. Hsu et al. have given the equation for $\left|V_{R P}\right|$ [50]:

$$
\left|V_{R P}\right|=\frac{\Delta E_{R P}}{2}
$$

According to Koopmans approximation, the $\Delta E_{R P}$ is derived from [51,52]:

$$
\Delta E_{R P}=E_{0-0}^{d y e}-\left[2 E_{o x}^{d y e}+E_{R E D}^{d y e}+E_{C B}^{T i O_{2}}\right]
$$

Preat's theoretical method shows the calculation method of $\Delta G_{\text {inject }}$ [53]:

$$
\Delta G^{\text {inject }}=E_{o x}^{\text {dye* }}-E_{C B}^{S C}
$$

Here $E_{o x}^{d y e *}$ represents the oxidation potential of the dye in the excited state, $E_{C B}^{S C}$ represents the reduction potential of $\mathrm{TiO}_{2}$ semiconductor [54] $\left(E_{C B}^{S C}=4.0 \mathrm{eV}\right)$ Thereunto $E_{o x}^{\text {dye* }}$ can also be expressed as:

$$
E_{o x}^{d y e *}=E_{o x}^{d y e}-\lambda_{\max }
$$

where $E_{o x}^{d y e}$ represents the oxidation reduction potential of the ground state, $\lambda_{\max }$ represents the energy of the ICT. Higher oxidation potentials can result in greater driving force for the injection.

As show in Table 5, the $E_{o x}^{d y e *}$, the $\Delta G_{\text {inject, }}$ and $\left|V_{R P}\right|$ of LS-385, LS-386 and LS-387 were calculated. The oxidation potential $\left(E_{o x}^{d y e *}\right)$ of the three dyes in vacuum is as follows: LS-387 $(2.364 \mathrm{eV})<$ LS-386 $(2.658 \mathrm{eV}) \approx$ LS-385 $(2.654 \mathrm{eV})$, and in solvent is as follows: LS-387 $(2.449 \mathrm{eV})<$ LS-386 $(2.677 \mathrm{eV})$ $<$ LS-385 $(2.681 \mathrm{eV})$; so LS-387 has a lower value of $E_{o x}^{\text {dye* }}$ in vacuum and solvent. Lower $E_{o x}^{\text {dye* }}$ will result in easier photooxidation.

The value of $\Delta G^{\text {inject }}$ is negative, which means that dye excited states can easily inject electrons into $\mathrm{TiO}_{2} \mathrm{CB}$. As shown in Table 5, the absolute value of the $\Delta G^{\text {inject }}$ of the three dyes in vacuum can be arranged in sequence: LS-387 $(1.636 \mathrm{eV})>$ LS-385 $(1.346 \mathrm{eV})>$ LS-386 $(1.342 \mathrm{eV})$, and the $\Delta G^{\text {inject }}$ of the three molecules is higher than $0.2 \mathrm{eV}$, which also shows that the molecular excited states can smoothly inject electrons into the $\mathrm{TiO}_{2} \mathrm{CB}$. Moreover, the absolute value of $\Delta G^{\text {inject }}$ for LS-387 is much larger than LS-385 and LS-386. Therefore, LS-387 has the higher $\Delta G^{\text {inject }}$; Table 5 also lists the coupling constant $\left(V_{R P}\right)$ in vacuum and solvent, in which LS-387 has the higher $V_{R P}$ compared with LS-385 and LS-386. Therefore, LS-387 will produce a higher $J_{S C}$ and further improve efficiency.

The dye regeneration free energy $\left(\Delta G_{d y e}^{\text {regen }}\right)$ can be used to characterize the regeneration ability of dye molecules from $I^{-} / I^{3-}$ electrolyte; the higher the $\Delta G_{d y e}^{\text {regen }}$ drive, the better the regenerative capacity and electron transport capacity of the dye become. $\Delta G_{\text {dye }}^{\text {regen }}$ can be calculated as the difference between the redox potential of $I^{-} / I^{3-}\left(E_{\text {redox }}^{\text {electrolyte }}=-4.60 \mathrm{eV}\right)[55,56]$ and $E_{\text {ox }}^{\text {dye }}$. Table 5 shows the $\Delta G_{\text {dye }}^{\text {regen }}$ of the three dyes can be arranged: LS $-385(0.995 \mathrm{eV})>\mathrm{LS}-386(0.964 \mathrm{eV})>\mathrm{LS}-387(0.525 \mathrm{eV})$; and dyes in the solvent follow the same sequence. The values of $\Delta G_{d y e}^{\text {regen }}$ of the three dyes in vacuum and solvent are higher than $0.5 \mathrm{eV}$, which means that the three dyes can finalize the regenerative process.

An important parameter to study charge transfer efficiency is the excited state lifetime $(\tau)$, which can be evaluated via the following equation:

$$
\tau=\frac{1.499}{f \times E^{2}}
$$

where $E$ represents the excitation energy of the different electronic states $\left(\mathrm{cm}^{-1}\right)$ and $\mathrm{f}$ is the oscillator strength. Relevant data are in Table 6. The $\tau$ of the three dyes are arranged in sequence: LS 386 (1.82 ns) 
$<$ LS-385 (2.02 ns) < LS-387 (2.29 ns). Intuitive data shows that LS-387 maintains long-term stability in the cationic state.

Table 6. The excited state lifetime of ( $\tau$, in ns) in DMF solvent.

\begin{tabular}{cccc}
\hline & LS-385 & LS-386 & LS-387 \\
\hline$\tau(\mathrm{ns})$ & 2.02 & 1.82 & 2.29 \\
\hline
\end{tabular}

The $V_{O C}$ represents the difference between the quasi-Fermi level (electrons in the titanium dioxide conduction band) and the redox potential (electrolyte) [57]. Movement of the $E_{C B}$ after the dye adsorption on the semiconductor substrate directly affects the $V_{O C}$, and the relationship between the movement of the $E_{C B}$ and adsorbed molecular characteristics can be written as [31,58]:

$$
\Delta E_{C B}=\frac{-q \mu_{\text {normol }} \gamma}{\varepsilon_{0} \varepsilon}
$$

where $\mu_{\text {normol }}$ is the dipole moment component of the dye molecules perpendicular to the surface of $\mathrm{TiO}_{2}, \gamma$ is the absorption concentration of the semiconductor surface, and $\varepsilon_{0}$ and $\varepsilon$ represent the dielectric constant and the organic monolayer in vacuum, respectively. The dyes with larger $\mu_{\text {normol }}$ and $\Delta E_{C B}$ will generate a larger $V_{O C}$. Figure 6a shows that for isolated dyes, the $\mu_{\text {normol }}$ (in Debye) of LS-387 (12.9878D) is the largest compared with LS-385 and LS-386; for dye/( $\left.\mathrm{TiO}_{2}\right)_{9}$, the value of $\mu_{\text {normol }}$ should follow the sequence of LS-387 > LS-385 > LS-386 (see Figure 6b). Therefore, the high $V_{O C}$ of LS-387 can be contributed to the larger $\mu_{\text {normol }}$ of LS-387, which is in good agreement with the experimental results [16].
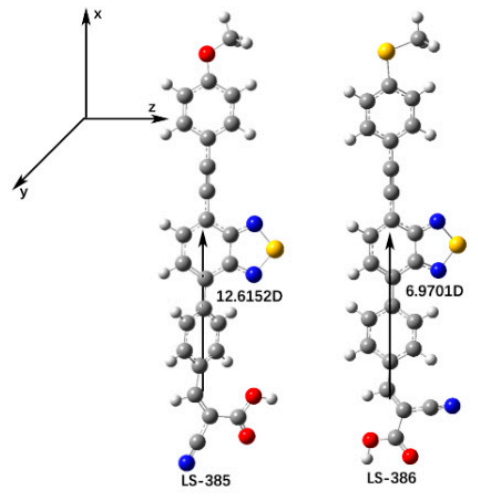

(a)

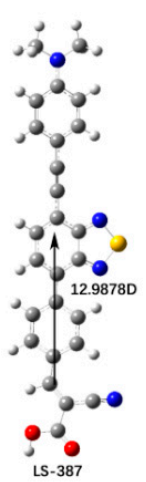

LS-387

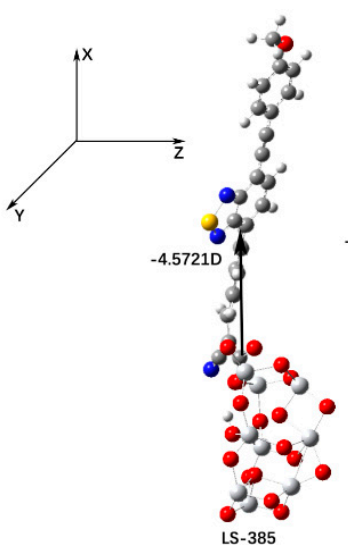

(b)
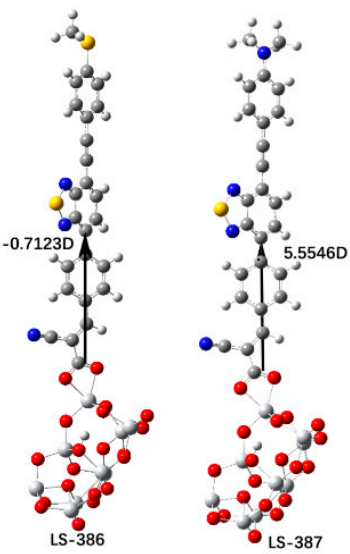

Figure 6. (a) Calculated vertical dipole moment $\mu_{\text {normol }}$ of dye in DMF solvent. (b) Calculated vertical dipole moment $\mu_{\text {normol }}$ of dye $/\left(\mathrm{TiO}_{2}\right)_{9}$ complexes in DMF solvent.

\subsection{Analysis of Recombinant Active Site}

It is very important to gain electrons in the regeneration process of dyes. Molecular surface electrostatic potential (ESP) [59] and average local ionization energy (ALIE) [60] can be used to determine the active sites of electrolyte and dye cations in the active region. A higher ESP site means the site attracts the strongest nucleophilic agent and is most likely to interact with the negatively charged electrolyte [37]. One of the most important roles of ALIE is to predict the reaction sites for electrophilic or free radical attack. The minimum value of surface ALIE can effectively reveal which atoms are more likely to be the preferred location for electrophilic or free radical attack. The relevant data and images are summarized in Figure 7. As shown, the minima of ALIE distributed near the donor atom $(\mathrm{O}, \mathrm{S}, \mathrm{N})$, and LS-387 has a smaller value than LS-385 and LS-386. Furthermore, in the 
donor site, the maxima ESP have a concentrated distribution near the $\mathrm{N}$ atom site of LS-387. It seems that the main atoms $\mathrm{O}, \mathrm{S}, \mathrm{N}$ of donor complement can serve as active sites for dye molecules and electrolytes. The extreme points of ALIE and ESP determine that the donor site may be a point of interest for electrolyte ions.

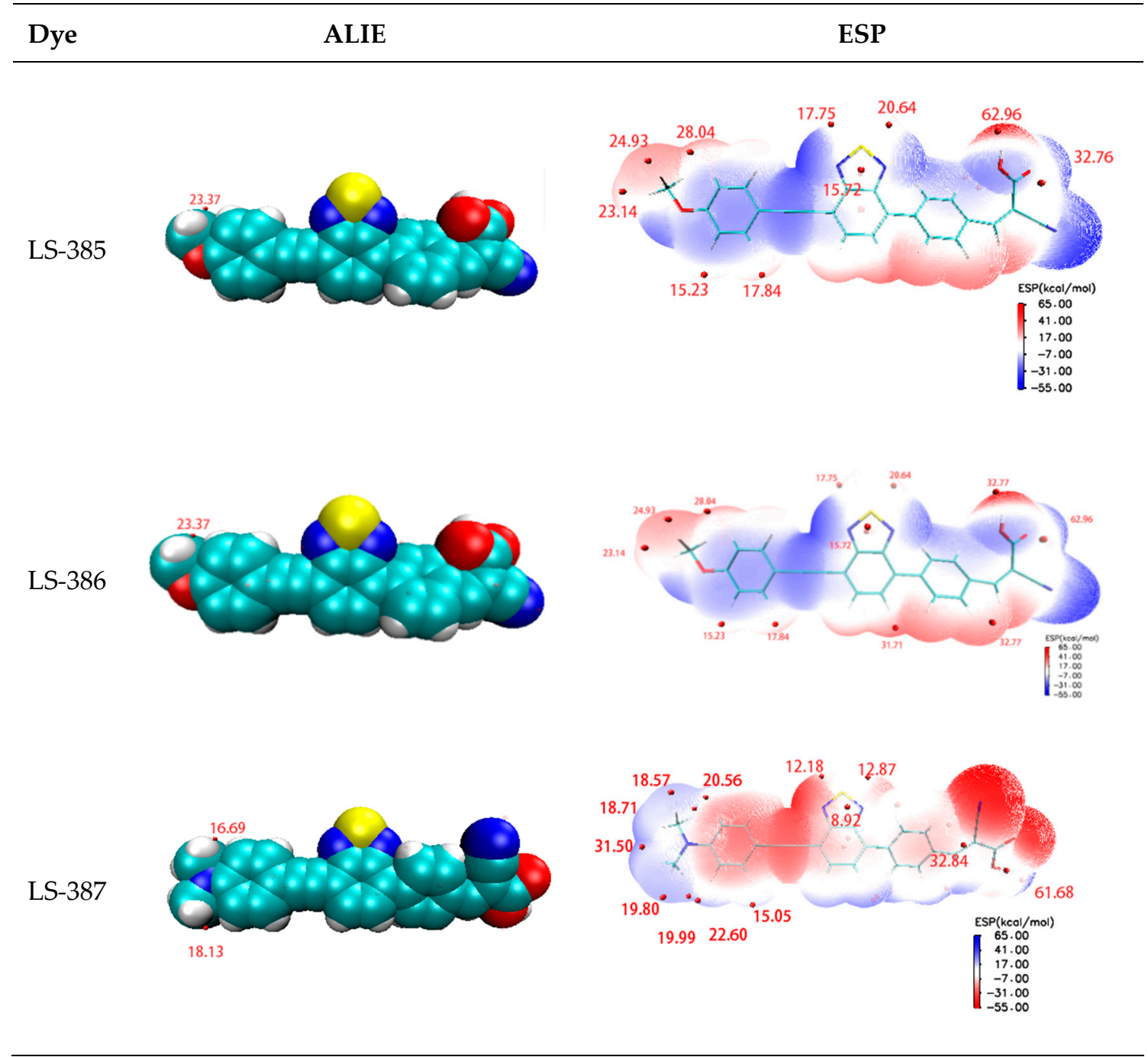

Figure 7. Graphical representation for minima of ALIE on VMD surface and local maxima of ESP on VMD surface of the dye cations of LS- $385^{+}$, LS- $386^{+}$, and LS- $387^{+}$. The extrema ALIE (in eV) and ESP (in $\mathrm{kcal} / \mathrm{mol}$ ) points near to the donor regions are marked.

\subsection{First Hyperpolarizability}

The first static hyperpolarizability is viewed as third-order tensor and second-order nonlinear optical response (NLO) coefficient [61]. Table S3 shows that the direction of the first hyperpolarizability (positive value) is in the same direction as the $\mathrm{X}$ axis, which also means that the three molecules have the same direction of charge transfer. LS-387 has a higher first hyperpolarizability, which may be due to the planar structure between the $\pi$ bridge and the acceptor (see Table 1). This facilitates the better ICT of electrons from the donor to the acceptor and accelerates electron injection from the dye molecules to the $\mathrm{TiO}_{2} \mathrm{CB}$. 


\subsection{Molecular Design}

By analyzing the photoelectric properties of the original dyes, we can obtain the conclusion that the parameters of LS-387 are superior to the others; as a result, LS-387 produces better $\operatorname{PCE}(\eta=5.61 \%[16])$. DFT provides a design strategy for controlling performance from the viewpoint of theory [60-62]. Based on LS-387, we theoretically designed fifteen new dye molecules to improve the electro-optical performance. On the donor group, we symmetrically introduced to the electron donating substituents $\left(-\mathrm{OH},-\mathrm{NH}_{2}\right.$ and $\left.-\mathrm{OCH}_{3}\right)$; on the molecule's acceptor group, the electron-acceptors $\left(-\mathrm{CF}_{3},-\mathrm{F}\right.$ and $-\mathrm{CN}$ ). By introducing different groups, we reduced the molecular energy gap, which is conducive to a red-shift of the absorption spectrum; at the same time, the introduction of individual groups can improve the dye regeneration free energy to some extent, thus improving the regeneration efficiency $\left(\eta_{\text {reg }}\right)$ and $J_{S C}$ of the dyes. On LS-387, we defined five positions $\left(R_{1}-R_{5}\right)$ to introduce electron groups (see Figure 8). Also, in $R_{1}$ and $R_{2}$, three donor groups were introduced, where the molecules are named: LS-387-X ( $\mathrm{X}=1 \mathrm{~A}, 1 \mathrm{~B}, 1 \mathrm{C}, 12 \mathrm{~A}, 12 \mathrm{~B}$ and $12 \mathrm{C})$; and in the acceptor group $\left(R_{3}, R_{4}\right.$, and $\left.R_{5}\right)$, we introduced three electron-acceptors, where the molecules are named: LS-387-Y $(\mathrm{Y}=3 \mathrm{D}, 3 \mathrm{E}, 3 \mathrm{~F}, 4 \mathrm{D}, 4 \mathrm{E}$, $4 \mathrm{~F}, 5 \mathrm{D}, 5 \mathrm{E}$ and $5 \mathrm{~F})$.

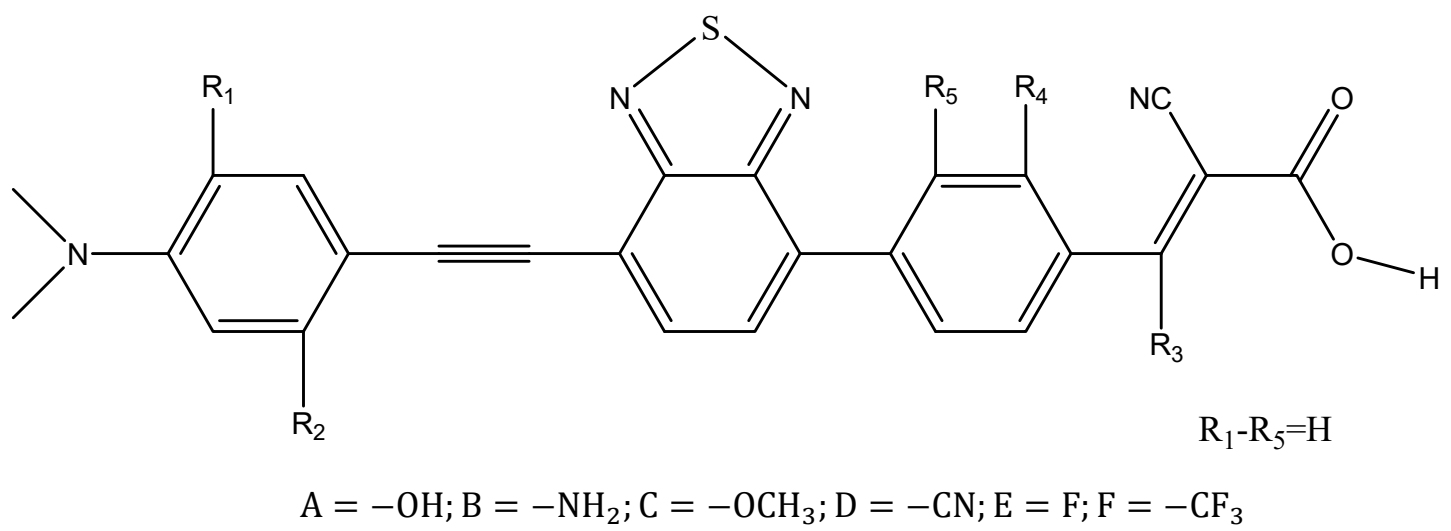

Figure 8. Molecular structures of dye LS-387 and designed molecules (LS-387-X and LS-387-Y).

The molecules (LS-387-X and LS-387-Y) ground state were optimized in DMF solvent, and bond length and dihedral angle are listed in Tables S4 and S5. As shown in Table S4, the bond length $\left(d_{1}\right.$ to $\left.d_{6}\right)$ of LS-387-1A (1B and 1C) is not obviously changed compared with LS-387; However, the $d_{1}$ of LS-387-12A (12B and 12C) is higher than LS-387. It seems that introducing into two of the same electron groups leads to larger bond length that can affect the stability of the molecules. In addition, in the acceptor group, the $d_{5}$ and $d_{6}$ of LS-387-3D (3E, 3F, 4D, 4E, 4F, 5D, 5E and 5F) is greater than LS-387, but the $d_{1}-d_{4}$ is not obviously changed compared with LS-387. Therefore, the electronic groups introduced by the acceptors are also not conducive to improving the stability of the molecules. As shown in Table S5, the dihedral angle $(\angle 1)$ of LS-387-X $(X=1 \mathrm{~A}, 1 \mathrm{~B}, 1 \mathrm{C}, 12 \mathrm{~A}, 12 \mathrm{~B}$ and $12 \mathrm{C})$ is not obviously changed compared to LS-387; for the dihedral angle $\angle 2$, the LS-387-12C (-0.062) has a smaller value than LS-387, and the molecule is more planar in the acceptor site, which is beneficial to ICT. For LS-387-Y, due to the interatomic repulsive effect of the group, the increases of $\angle 1$ and $\angle 2$ will be different, and the ICT will have a negative effect.

Figure 9 shows the HOMO, LUMO energy level and the energy gap $(\Delta \mathrm{G}=\mid \mathrm{H}-\mathrm{LI})$, and data are listed in Table S6. The energy gap of LS-387-1B and LS-387-12B is $2.072 \mathrm{eV}$ and $1.921 \mathrm{eV}$, and the higher HOMO energy level of LS-387-1B and LS-387-12B will result in a small gap (see Figure 9a). Because a narrow energy gap is favorable to red-shift absorption, the smaller energy gap for LS-387-1B and LS-387-12B by introducing $-\mathrm{NH}_{2}$ will lead to a larger absorption peak. For acceptor designed molecules LS-387-Y, the LS-387-3D (1.676 eV), LS-387-4D (2.115 eV), and LS-387-5D (2.128 eV) have a lower gap (see Figure 9b), which is due to lower LUMO level for LS-387-Y (3D, 4D and 5D). To sum up, the introduction of the $-\mathrm{NH}_{2}$ group at the donor site and the introduction of $-\mathrm{CN}$ at the acceptor 
site can reduce the gap, thus leading to a red-shift in the maximum absorption peak and improvement of the light trapping efficiency.

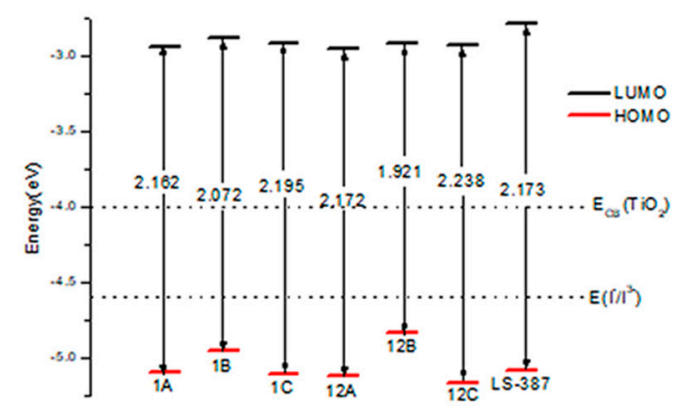

(a)

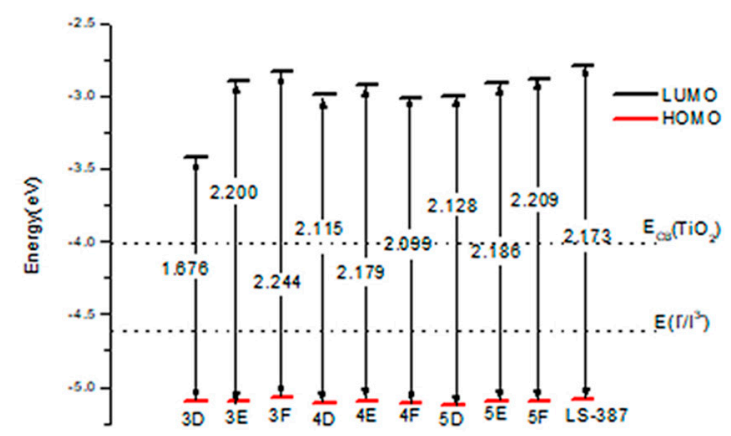

(b)

Figure 9. Energy level in solvent of LS-387-based designed molecules, where (a) is LS-387-X (X=1A, $1 \mathrm{~B}, 1 \mathrm{C} 12 \mathrm{~A}, 12 \mathrm{~B}$ and $12 \mathrm{C}),(\mathbf{b})$ is LS-387-Y ( $=3 \mathrm{D}, 3 \mathrm{E}, 3 \mathrm{~F}, 4 \mathrm{D}, 4 \mathrm{E}, 4 \mathrm{~F}, 5 \mathrm{D}, 5 \mathrm{E}$ and $5 \mathrm{~F})$.

The excited state characteristics of the design molecules were calculated, and the results are listed in Table S7. As shown in Table S7, the LS-387-1B and the LS-387-12B have the $\lambda_{\max }$ of $496.16 \mathrm{~nm}$ and $490.19 \mathrm{~nm}$, which is larger than LS-387 (470.40 nm). So dye LS-387-1B and LS-387-12B have a red-shift of 20-25 nm. The first excited states of LS-387-1B and LS-387-12B show an electron transition of HOMO $\rightarrow$ LUMO (see Figure S2). While for the LS-387-3D, its $\lambda_{\max }$ (an electron transition is $\mathrm{HOMO} \rightarrow \mathrm{LUMO}$ ) is found to be $485.58 \mathrm{~nm}$, which configuration will produce a larger red-shift relative to the original molecule. Figure $\mathrm{S} 3$ shows absorption spectra of 15 designed molecules, which show that LS-387-1B and LS-387-12B have obvious red-shifted absorption (LS-387-3D has an obvious absorption peak red-shifted relative to the original molecules). In summary, it was found that the design by introducing the $-\mathrm{NH}_{2}$ group individually or in pairs on the donor site should reduce the energy gap and make the spectrum red-shifted, and then improve the ICT; introducing on the acceptor site $R_{3}$ position $-\mathrm{CN}$ groups has a similar trend.

From Section 3.4, IP and EA are important injection parameters, and $E_{f u n d}$ can be used to characterize the electronic contribution of dye molecules [62-64]. The LS-387-1B (12A, 12B and 12C) has a lower value of IP compared with LS-387 (see Table S8), and the EA of LS-387-3D has a large value relative to LS-387 and other designed molecules. Therefore, LS-387-1B (12A, 12B and 12C) will produce a higher outcome of extracting electrons, and LS-387-3D will have a better absorbing ability of electrons. The $E_{f u n d}$ of LS-387-3D produced a lower value relative to the original molecule and other designed molecules, therefore, LS-387-3D will show better electronic ability.

On the basis of the ground state optimizations of fifteen designed molecules, four electrochemical activity parameters are also listed in Table S8. The h of LS-387-1B (12A, 12B and 12C) has a significant decrease compared with LS-387 (0.88). Among the above three designed dyes, for LS-387-1B (12B) the introduction of $-\mathrm{NH}_{2}$ in the donor terminal reduces the chemical hardness of the dyes more effectively than other introductions of $-\mathrm{OCH}_{3}$ and $-\mathrm{OH}$. The LS-387-3D (4D and 5D) and the LS-387-3E also has a lower h compared with LS-387. In summary, introduction of two electron groups $\left(-\mathrm{NH}_{2}\right)$ in the donor site or the introduction of $R_{3}\left(-\mathrm{CF}_{3}\right.$ and $\left.-\mathrm{CN}\right)$ in the acceptor are more beneficial to reducing the $\mathrm{h}$ of the dye molecules. Moreover, the dyes of LS-387-12A (12B and 12C) have a higher $\omega^{+}$compared to LS-387 and LS-387-1A (1B and 1C). LS-387-3D (13.17) and LS-387-3F (9.76) also has a maximum value of $\omega^{+}$. So, introduction of electron-donating groups $\left(-\mathrm{NH}_{2}\right)$ in pairs on the donor site and introduction of $-\mathrm{CF}_{3}$ and $-\mathrm{CN}$ in the acceptor site $R_{3}$ were beneficial to increase the $\omega^{+}$dye molecules. Therefore, the above two parameters indicated that LS-387-12B and LS-387-3D (3F) would have a higher $J_{S C}$. The higher absolute value of $\Delta G^{\text {inject }}$ can lead spontaneously to inject electrons to $\mathrm{TiO}_{2}$. Table 7 shows that LS-387-1B (12B) has a higher absolute value of $\Delta G^{\text {inject }}$ compared with dye LS-387. The higher 
HOMO levels of LS-387-1B (12B) lead to greater $\Delta G^{\text {inject }}$ (see Figure 9a). The introduction of the $-\mathrm{NH}_{2}$ group is helpful to increase the electron injection, and introduction of two $-\mathrm{NH}_{2}$ groups can still further increase the electron injection compared with single introduction of $-\mathrm{NH}_{2}$. Also, the coupling constant $\left(V_{R P}\right)$ is listed in Table 7. For serials LS-387-X, LS-387-1B (12B) has the higher $V_{R P}$ compared with LS-387 and the other five dyes, which means that faster electron injection can occur for LS-387-1B (12B). The dye regeneration free energy $\left(\Delta G_{d y e}^{\text {regen }}\right)$ has important effects on the PCE. As shown in Table 7 , for LS-387-X, LS-387-12A (12C) has a higher value of $\Delta G_{\text {dye }}^{\text {regen }}$ compared with other dyes, indicating that two groups $-\mathrm{OH}$ and $-\mathrm{OCH}_{3}$ are beneficial to improve the free energy of the dye regeneration. In addition, for LS-387-3D ( $4 \mathrm{D}$ and $5 \mathrm{D}$ ), the $\Delta G_{\text {dye }}^{\text {regen }}$ is large than LS-387, showing that the $-\mathrm{CN}$ radical group is helpful to improve the free energy of the dye regeneration. The larger $\Delta G_{\text {dye }}^{\text {regen }}$ is beneficial to improve $\eta_{\text {reg }}$ and increase $J_{S C}$. Considering the above three properties $\left(\Delta G^{\text {inject }}, \Delta G_{d y e}^{\text {regen }}\right.$ and LHE), the $J_{S C}$ of LS-387-1B (12B) and LS-387-3D (4D and 5D) will be better than LS-387.

Table 7. Chemical parameters in DMF solvent. $\left(\Delta G^{\text {inject }}, \Delta G_{\text {dye }}^{\text {regen }}, E_{o x}^{\text {dye }}\right.$ and $E_{o x}^{\text {dye* }}$, in $\mathrm{eV} ; \mu_{\text {normol }}$, in Debye).

\begin{tabular}{cccccccc}
\hline Dyes & LHE & $\Delta G^{\text {inject }}$ & $\Delta G_{\text {dye }}^{\text {regen }}$ & $E_{\text {ox }}^{\text {dye }}$ & $E_{\text {ox }}^{\text {dye* }}$ & $V_{\boldsymbol{R P}}$ & $\boldsymbol{\mu}_{\text {normol }}$ \\
\hline LS-387-1A & 0.9636 & -1.512 & 0.499 & 5.099 & 2.489 & 0.756 & 11.5551 \\
LS-387-1B & 0.9585 & -1.538 & 0.361 & 4.961 & 2.462 & 0.769 & 13.3062 \\
LS-387-1C & 0.9634 & -1.529 & 0.509 & 5.109 & 2.471 & 0.765 & 12.9133 \\
LS-387-3D & 0.9584 & -1.453 & 0.500 & 5.100 & 2.547 & 0.727 & 12.5191 \\
LS-387-3E & 0.9563 & -1.558 & 0.493 & 5.093 & 2.442 & 0.779 & 12.9292 \\
LS-387-3F & 0.9349 & -1.650 & 0.470 & 5.070 & 2.350 & 0.825 & 9.1245 \\
LS-387-4D & 0.9503 & -1.538 & 0.508 & 5.108 & 2.462 & 0.769 & 14.0796 \\
LS-387-4E & 0.9605 & -1.531 & 0.499 & 5.099 & 2.469 & 0.766 & 13.8853 \\
LS-387-4F & 0.9598 & -1.510 & 0.505 & 5.105 & 2.490 & 0.755 & 13.1415 \\
LS-387-5D & 0.9458 & -1.574 & 0.525 & 5.125 & 2.426 & 0.787 & 10.6711 \\
LS-387-5E & 0.9500 & -1.628 & 0.498 & 5.098 & 2.372 & 0.814 & 11.4385 \\
LS-387-5F & 0.9272 & -1.713 & 0.495 & 5.095 & 2.287 & 0.857 & 11.0183 \\
LS-387-12A & 0.9609 & -1.545 & 0.524 & 5.124 & 2.455 & 0.773 & 7.3461 \\
LS-387-12B & 0.9323 & -1.687 & 0.242 & 4.842 & 2.313 & 0.844 & 10.3030 \\
LS-387-12C & 0.9642 & -1.503 & 0.566 & 5.166 & 2.497 & 0.752 & 12.3172 \\
\hline
\end{tabular}

Table 7 shows the $\mu_{\text {normol }}$ of fifteen designed molecules, and for LS-387-X, the LS-387-1B has a higher $\mu_{\text {normol }}$ compared with LS-387; for LS-387-Y, the dyes of LS-387-4D (4E and 4F) have higher $\mu_{\text {normol }}$ compared with LS-387. In summary, introduction of electron-donating groups $\left(-\mathrm{NH}_{2}\right)$ on the donor site and introduction of electron-acceptor groups $\left(-\mathrm{CN},-\mathrm{F}\right.$ and $\left.-\mathrm{CF}_{3}\right)$ on the acceptor site $R_{4}$ are beneficial for the improvement of $\mu_{\text {normol }}$, which then improves the $V_{O C}$.

\section{Conclusions}

This paper systematically studied the photoelectric properties of three basic dye molecules with DFT calculations from the following aspects (structures, energy levels, spectra, electron transfer process, and chemical parameters etc.). We inferred some common conclusions: (a) LS-387 has a shorter bond length and smaller dihedral angle, which is of benefit to the ICT. (b) LS-387 displays higher HOMO and narrow gap, which leads to stronger electron donating ability and a broad absorption spectrum; (c) Analysis by CDD shows that LS-387 can effectively improve charge separation, which is supported by NBO analysis; (d) the well experimental performance of $J_{S C}$ and $V_{O C}$ for LS-387 can contribute to higher $\Delta G^{\text {inject }}$ and LHE as well as $\mu_{\text {normol }}$; (e) fifteen dyes were designed with pull-push electron groups in donor and acceptor, and it was found that the rational introduction of electron groups $\left(-\mathrm{NH}_{2},-\mathrm{CN},-\mathrm{F}\right.$ and $\left.-\mathrm{CF}_{3}\right)$ in the molecule can effectively improve the photoelectric properties of dyes. The above discussion can provide a theoretical basis for achieving higher performance of DSSC. 
Supplementary Materials: The following are available online at http:/ / www.mdpi.com/1996-1944/11/10/2027/ s1, Figure S1. Charge difference density (CDD) of the selected excited state for dyes in solvent. (Green and red stand for the hole and electron, respectively), Figure S2. Frontier molecular orbital of molecular designing in DMF solvent. Figure S3. The UV-Vis absorption spectrum in DMF solvent. Table S1. Energy levels of HOMO and LUMO and energy gaps calculated by DFT in vacuum and DMF solvent of three dyes. Table S2. The ionization potentials(IP) and electron affinities(EA) of LS-385, LS-386 and LS-387 in vacuum and solvent. Table S3. Calculated the static first hyperpolarizability of the three dyes in vacuum and DMF solvent. Table S4. The bond length of LS-387 analogous in DMF solvent. Table S5. Dihedral angle in DMF solvent. Table S6. The energy level and the energy gap in DMF solvent. Table S7. Transition energies $\left(E_{g}\right)$ and oscillator strengths of 15 designed molecules in DMF solvent. Table S8. The Electrochemical Parameter in DMF solvent. Cartesian coordinates of the optimized structure.

Author Contributions: Conceptualization: Y.L. and Y.Y.; Funding acquisition: Y.L.; Investigation and data analysis: N.G., X.L. and J.L.; Software: N.G. and Y.L.; Writing—original draft: N.G.; Writing—review \& editing: N.G., Y.L. and Y.Y.

Funding: The Fundamental Research Funds for the Central Universities (2572018BC24), Heilongjiang Postdoctoral Grant (LBH-Z15002), the China Postdoctoral Science Foundation (2016M590270), the college students' innovation project of NEFU (201709000001) and the National Natural Science Foundation of China (Grant Nos. 11404055 and 11374353).

Acknowledgments: This work was supported by the Fundamental Research Funds for the Central Universities (2572018BC24), Heilongjiang Postdoctoral Grant (LBH-Z15002), the China Postdoctoral Science Foundation (2016M590270), the college students' innovation project of NEFU (201709000001) and the National Natural Science Foundation of China (Grant Nos. 11404055 and 11374353).

Conflicts of Interest: The authors declare no conflict of interest.

\section{References}

1. O'regan, B.; Grätzel, M. A Low-Cost, High-efficiency solar cell based on dyesensitized colloidal TiO ${ }_{2}$ films. Nature 1991, 353, 737-740. [CrossRef]

2. Ren, Y.; Sun, D.; Cao, Y.; Tsao, H.N.; Yuan, Y.; Zakeeruddin, S.M.; Wang, P.; Gratzel, M. A Stable Blue Photosensitizer for Color Palette of Dye-Sensitized Solar Cells Reaching 12.6\% Efficiency. J. Am. Chem. Soc. 2018, 140, 2405-2408. [CrossRef] [PubMed]

3. Hagfeldt, A.; Boschloo, G.; Sun, L.; Kloo, L.; Pettersson, H. Dye-sensitized solar cells. Chem. Rev. 2010, 110, 6595-6663. [CrossRef] [PubMed]

4. Kakiage, K.; Aoyama, Y.; Yano, T.; Oya, K.; Fujisawa, J.I.; Hanaya, M. Highly-efficient dye-sensitized solar cells with collaborative sensitization by silyl-anchor and carboxy-anchor dyes. Chem. Commun. (Cambridge) 2015, 51, 15894-15897. [CrossRef] [PubMed]

5. Mishra, A.; Fischer, M.K.; Bäuerle, P. Metal-free organic dyes for dye-sensitized solar cells: From structure: Property relationships to design rules. Angew. Chem. Int. Ed. 2009, 48, 2474-2499. [CrossRef] [PubMed]

6. Meng, L.; Ren, T.; Li, C. The control of the diameter of the nanorods prepared by dc reactive magnetron sputtering and the applications for DSSC. Appl. Surf. Sci. 2010, 256, 3676-3682. [CrossRef]

7. Ünlü, B.; Çakar, S.; Özacar, M. The effects of metal doped $\mathrm{TiO}_{2}$ and dithizone-metal complexes on DSSCs performance. Sol. Energy 2018, 166, 441-449. [CrossRef]

8. Robertson, N. Optimizing dyes for dye-sensitized solar cells. Angew. Chemie. Int. Ed. 2006, 45, $2338-2345$. [CrossRef] [PubMed]

9. Han, F.; Wang, Y.; Wan, Z.; Jia, C.; Luo, J.; Yao, X. Enhanced photovoltaic performances of dye-sensitized solar cells sensitized with D-D- $\pi$-A phenothiazine-based dyes. Synth. Met. 2016, 221, 95-102. [CrossRef]

10. Li, Y.Z.; Li, Y.C.; Song, P.; Ma, F.C.; Yang, Y.H. Electric field effect on multi-anchoring molecular architectures: Electron transfer process and opto-electronic property. J. Mol. Liq. 2018, 261, 123-136. [CrossRef]

11. Geiger, T.; Kuster, S.; Yum, J.H.; Moon, S.J. Molecular Design of Unsymmetrical Squaraine Dyes for High Efficiency Conversion of Low Energy Photons into Electrons Using $\mathrm{TiO}_{2}$ Nanocrystalline Films. Adv. Funct. Mater. 2009, 19, 2720-2727. [CrossRef]

12. Paek, S.; Choi, H.; Kim, C.; Cho, N.; So, S.; Song, K.; Ko, J. Efficient and Stable panchromatic squaraine dyes for dye-sensitized solar cells. Chem. Commu. (Cambridge) 2011, 47, 2874-2876. [CrossRef] [PubMed]

13. Ito, S.; Miura, H.; Uchida, S.; Takata, M.; Sumioka, K.; Liska, P.; Grätzel, M. High-conversion-efficiency organic dye-sensitized solar cells with a novel indoline dye. Chem. Commun. (Cambridge) 2008, 41, 5194-5196. [CrossRef] [PubMed] 
14. Naik, P.; Elmorsy, M.R.; Su, R.; Babu, D.D.; El-Shafei, A.; Adhikari, A.V. New carbazole based metal-free organic dyes with D- $\pi-\mathrm{A}-\pi-\mathrm{A}$ architecture for DSSCs: Synthesis, theoretical and cell performance studies. Sol. Energy 2017, 153, 600-610. [CrossRef]

15. Wang, G.; Liu, Z.; Deng, Y.; Xie, L.; Tan, S. Comparative study on N,N-di-p-tolylaniline-based D- $\pi$-A1- $\pi$-A2 sensitizers by tuning the auxiliary acceptor for dye-sensitized solar cells. Dyes Pigment. 2017, 145, 427-435. [CrossRef]

16. Park, K.W.; Serrano, L.A.; Ahn, S.; Baek, M.H.; Wiles, A.A.; Cooke, G.; Hong, J. An investigation of the role the donor moiety plays in modulating the efficiency of 'donor- $\pi$-acceptor- $\pi$-acceptor' organic DSSCs. Tetrahedron 2017, 73, 1098-1104. [CrossRef]

17. Bendjabeur, S.; Zouaghi, R.; Zouchoune, B.; Sehili, T. DFT and TD-DFT insights, photolysis and photocatalysis investigation of three dyes with similar structure under UV irradiation with and without $\mathrm{TiO}_{2}$ as a catalyst: Effect of adsorption, $\mathrm{pH}$ and light intensity. Spectrochim. Acta Part A Mol. Biomol. Spectrosc. 2018, 190, 494-505. [CrossRef] [PubMed]

18. Zhang, C.R.; Liu, Z.J.; Chen, Y.H.; Chen, H.S.; Wu, Y.Z.; Feng, W.; Wang, D.B. DFT and TD-DFT study on structure and properties of organic dye sensitizer TA-St-CA. Curr. Appl. Phys. 2010, 10, 77-83. [CrossRef]

19. Ren, P.F.; Zhang, Y.H.; Luo, Z.W.; Song, P.; Li, Y.Z. Theoretical and experimental study on spectra, electronic structure and photoelectric properties of three nature dyes used for solar cells. J. Mol. Liq. 2017, 247, $193-206$. [CrossRef]

20. Frisch, M.J.; Trucks, G.W.; Schlegel, H.B.; Scuseria, G.E.; Robb, M.A.; Cheeseman, J.R.; Scalmani, G.; Barone, V.; Petersson, G.A.; Nakatsuji, H.; et al. Gaussian 09, Revision A.01; Gaussian, Inc.: Wallingford, CT, USA, 2009.

21. Lee, C.; Yang, W.; Parr, R.G. Development of the Colle-Salvetti correlation-energy formula into a functional of the electron density. Phys. Rev. B Condens. Matter 1988, 37, 785-789. [CrossRef]

22. Becke, A.D. Density-functional exchange-energy approximation with correct asymptotic behavior. Phys. Rev. A 1988, 38, 3098-3100. [CrossRef]

23. Gross, E.K.U.; Kohn, W. Local density-functional theory of frequency- dependent linear response. Phys. Rev. Lett. 1985, 55, 2850-2852. [CrossRef] [PubMed]

24. Yanai, T.; Tew, D.P.; Handy, N.C. A new hybrid exchange-correlation functional using the Coulomb-attenuating method (CAM-B3LYP). Chem. Phys. Lett. 2004, 393, 51-57. [CrossRef]

25. Foster, J.P.; Weinhold, F. Natural hybrid orbitals. J. Am. Chem. Soc. 1980, 102, 7211-7218. [CrossRef]

26. Glendening, E.D.; Landis, C.R.; Weinhold, F. NBO 6.0: Natural bond orbital analysis program. J. Comput. Chem. 2013, 34, 1429-1437. [CrossRef] [PubMed]

27. Lu, T.; Chen, F. Multiwfn: A multifunctional wavefunction analyzer. J. Comput. Chem. 2012, 33, 580-592. [CrossRef] [PubMed]

28. Humphrey, W.; Dalke, A.; Schulten, K. VMD: Visual molecular dynamics. J. Mol. Gr. 1996, 14, 33-38. [CrossRef]

29. Kleinman, D.A. Nonlinear Dielectric Polarization in Optical Media. Phys. Rev. 1962, 126, 1977-1979. [CrossRef]

30. Grätzel, M. Recent advances in sensitized mesoscopic solar cells. Acc. Chem. Res. 2009, 42, 1788-1798. [CrossRef] [PubMed]

31. Preat, J.; Jacquemin, D.; Perpete, E.A. Towards new efficient dye-sensitised solar cells. Energy Environ. Sci. 2010, 3, 891. [CrossRef]

32. Ardo, S.; Meyer, G.J. Photodriven heterogeneous charge transfer with transition-metal compounds anchored to $\mathrm{TiO}_{2}$ semiconductor surfaces. Chem. Soc. Rev. 2009, 38, 115-164. [CrossRef] [PubMed]

33. Hasselman, G.M.; Watson, D.F.; Stromberg, J.R.; Bocian, D.F.; Holten, D.; Lindsey, J.S.; Meyer, G.J. Theoretical solar-to-electrical energy- conversion efficiencies of Perylene-Porphyrin light-harvesting arrays. J. Phys. Chem. B 2006, 110, 25430-25440. [CrossRef] [PubMed]

34. Mo, Y.; Lin, Z.; Wu, W.; Zhang, Q. Bond-Distorted Orbitals and Effects of Hybridization and Resonance on C-C Bond Lengths. J. Phys. Chem. 1996, 100, 11569-11572. [CrossRef]

35. Li, Y.Z.; Sun, C.F.; Song, P.; Ma, F.C.; Yang, Y.H. Tuning the electron transport and accepting ability of dyes via introducing different $\pi$-conjugated bridges and acceptors for DSSCs. Chem. Phys. Chem. 2017, 18, 366-383. [CrossRef] [PubMed]

36. Li, Y.Z.; Xu, B.B.; Song, P.; Ma, F.C.; Sun, M.T. D-A- $-\pi-A$ System: Light Harvesting, Charge Transfer, and Molecular Designing. J. Phys. Chem. C 2017, 121, 12546-12561. [CrossRef] 
37. Baume, N.; Steel, G.; Edwards, T.; Thorstensen, E.; Miller, B.F. No variation of physical performance and perceived exertion after adrenal gland stimulation by synthetic ACTH (Synacthen) in cyclists. Eur. J. Appl. Phys. 2008, 104, 589-600. [CrossRef] [PubMed]

38. Song, P.; Li, Y.Z.; Ma, F.C.; Pullerits, T.; Sun, M.T. External Electric Field-Dependent Photoinduced Charge Transfer in a Donor-Acceptor System for an Organic Solar Cell. J. Phys. Chem. C 2013, 117, 15879-15889. [CrossRef]

39. Wang, J.G.; Mu, X.J.; Wang, X.X.; Wang, N.; Ma, F.C.; Liang, W.J.; Sun, M.T. The thermal and thermoelectric properties of in-plane C-BN hybrid structures and graphene/h-BN van der Waals heterostructures. Mater. Today Phys. 2018, 5, 29-57. [CrossRef]

40. Sun, M.T.; Yong, D.; Xu, H.X. Direct visual evidence for quinoidal charge delocalization in poly-p-phenylene cation radical. J. Phys. Chem. B 2007, 111, 13266-13270. [CrossRef] [PubMed]

41. Zhan, C.G.; Nichols, J.A.; Dixon, D.A. Ionization potential, electron affinity, electronegativity, hardness, and electron excitation energy: Molecular properties from density functional theory orbital energies. J. Phys. Chem. A 2003, 107, 4184-4195. [CrossRef]

42. Zhang, G.; Musgrave, C.B. Comparison of DFT methods for molecular orbital eigenvalue calculations. J. Phys. Chem. A 2007, 111, 1554-1561. [CrossRef] [PubMed]

43. Kotteswaran, S.; Senthil Pandian, M.; Ramasamy, P. Synthesis, optical, electrochemical and photovoltaic properties of donor modified organic dyes for dye-sensitized solar cell (DSSC) applications. J. Mater. Sci. Mater. Electron. 2018, 29, 6672-6678. [CrossRef]

44. Estrella, L.L.; Balanay, M.P.; Kim, D.H. The Effect of Donor Group Rigidification on the Electronic and Optical Properties of Arylamine-Based Metal-Free Dyes for Dye-Sensitized Solar Cells: A Computational Study. J. Phys. Chem. A 2016, 120, 5917-5927. [CrossRef] [PubMed]

45. Marcus, R.A. Electron transfer reactions in chemistry: Theory and experiment (Nobel lecture). Angew. Chem. Int. Ed. 1993, 32, 1111-1121. [CrossRef]

46. Tannous, B.A. Gaussia luciferase reporter assay for monitoring biological processes in culture and in vivo. Nat. Protoc. 2009, 4, 582-591. [CrossRef] [PubMed]

47. Parr, R.G.; Pearson, R.G. Absolute hardness: Companion parameter to absolute electronegativity. J. Am. Chem. Soc. 1983, 105, 7512-7516. [CrossRef]

48. Matthews, D.; Infelta, P.; Grätzel, M. Calculation of the photocurrent- potential characteristic for regenerative, sensitized semiconductor electrodes. Sol. Energy Mater. Sol. Cells 1996, 44, 119-155. [CrossRef]

49. Pourtois, G.; Beljonne, D.; Cornil, J.; Ratner, M.A.; Brédas, J.L. Photoinduced electron-transfer processes along molecular wires based on phenylenevinylene oligomers: A quantum-chemical insight. J. Am. Chem. Soc. 2002, 124, 4436-4447. [CrossRef] [PubMed]

50. Hsu, C.P. The electronic couplings in electron transfer and excitation energy transfer. Acc. Chem. Res. 2009, 42, 509-518. [CrossRef] [PubMed]

51. Koopmans, T. Über die Zuordnung von Wellenfunktionen und Eigenwerten zu den einzelnen Elektronen eines Atoms. Physical 1934, 1, 104-113. [CrossRef]

52. Al-Sehemi, A.G.; Irfan, A.; Asiri, A.M. The DFT investigations of the electron injection in hydrazone-based sensitizers. Theor. Chem. Acc. 2012, 131, 1199. [CrossRef]

53. Preat, J.; Michaux, C.; Jacquemin, D.; Perpete, E.A. Enhanced efficiency of organic dye-sensitized solar cells: Triphenylamine derivatives. J. Phys. Chem. C 2009, 113, 16821-16833. [CrossRef]

54. Asbury, J.B.; Wang, Y.Q.; Hao, E.; Ghosh, H.N.; Lian, T. Evidences of hot excited state electron injection from sensitizer molecules to $\mathrm{TiO}_{2}$ nanocrystalline thin films. Res. Chem. Int. 2001, 27, 393-406. [CrossRef]

55. Wang, X.; Xu, J.; Li, M.; Fang, D.; Chen, B.; Wang, L.; Xu, W. Highly efficient unsymmetrical squaraines for panchromatic dye-sensitized solar cells: A computational study. RSC Adv. 2013, 3, 5227. [CrossRef]

56. Pepe, G.; Cole, J.M.; Waddell, P.G.; Griffiths, J.R. Molecular engineering of fluorescein dyes as complementary absorbers in dye co-sensitized solar cells. Mol. Syst. Des. Eng. 2016, 1, 402-415. [CrossRef]

57. Ning, Z.T. Triarylamine: A promising core unit for efficient photovoltaic materials. Chem. Commu. (Cambridge) 2009, 37, 5483-5495. [CrossRef] [PubMed]

58. Rühle, S.; Greenshtein, M.; Chen, S.G.; Merson, A.; Pizem, H.; Sukenik, C.S.; Zaban, A. Molecular Adjustment of the Electronic Properties of Nanoporous Electrodes in Dye-Sensitized Solar Cells. J. Phys. Chem. B 2005, 109, 18907-18913. [CrossRef] [PubMed] 
59. Murray, J.S.; Politzer, P. The electrostatic potential: An overview. Wiley Interdiscip. Rev. Comput. Mol. Sci. 2011, 1, 153-163. [CrossRef]

60. Politzer, P.M.; Bulat, J.S. Average local ionization energy: A review. J. Mol. Model. 2010, 16, 1731-1742. [CrossRef] [PubMed]

61. Lu, D.; Chen, G.; Perry, J.W.; Goddard III, W.A. Valence-bond charge-transfer model for nonlinear optical properties of charge-transfer organic molecules. J. Am. Chem. Soc. 1994, 116, 10679-10685. [CrossRef]

62. Ali, B.A.; Allam, N.K. Propping the optical and electronic properties of potential photo-sensitizers with different $\pi$-spacers: TD-DFT insights. Spectrochim. Acta Part A Mol. Biomol. Spectrosc. 2018, 188, 237-243. [CrossRef] [PubMed]

63. Sharmoukh, W.; Hassan, W.M.I.; Gros, P.C.; Allam, N.K. Design and synthesis of new Ru-complexes as potential photo-sensitizers: Experimental and TD-DFT insights. RSC Adv. 2016, 6, 69647-69657. [CrossRef]

64. El-Shishtawy, R.M.; Elroby, S.A.; Asiri, A.M.; Mullen, K. Optical Absorption Spectra and Electronic Properties of Symmetric and Asymmetric Squaraine Dyes for Use in DSSC Solar Cells: DFT and TD-DFT Studies. Int. J. Mol. Sci. 2016, 17, 487. [CrossRef] [PubMed]

(C) 2018 by the authors. Licensee MDPI, Basel, Switzerland. This article is an open access article distributed under the terms and conditions of the Creative Commons Attribution (CC BY) license (http:/ / creativecommons.org/licenses/by/4.0/). 